\title{
Interlaboratory Round Robin Testing of SiC/SiC Composite Tubes
}

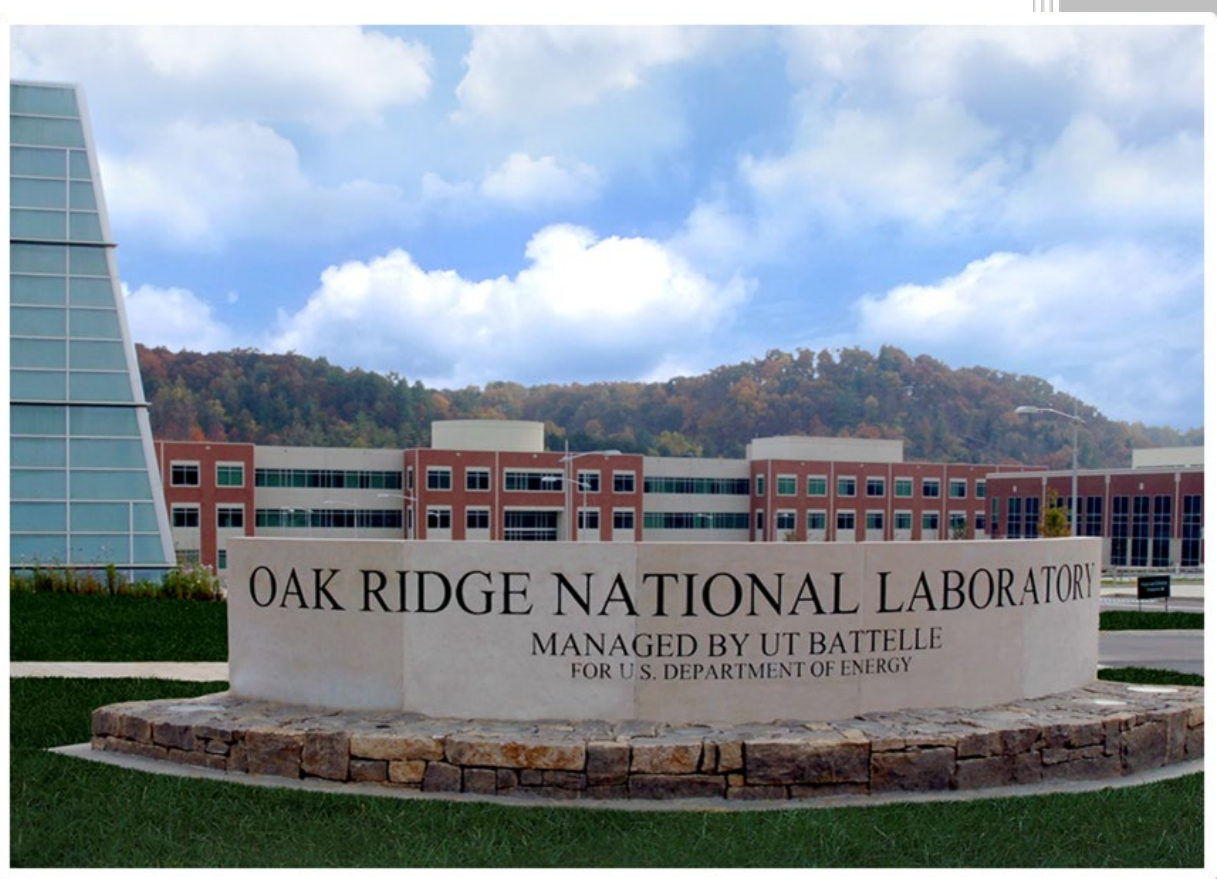

Approved for public release.

Distribution is unlimited.
Gyanender Singh Steve Gonczy Edgar Lara-Curzio Yutai Katoh

August 19, 2016 


\title{
DOCUMENT AVAILABILITY
}

Reports produced after January 1, 1996, are generally available free via US Department of Energy (DOE) SciTech Connect.

Website http://www.osti.gov/scitech/

Reports produced before January 1, 1996, may be purchased by members of the public from the following source:

\author{
National Technical Information Service \\ 5285 Port Royal Road \\ Springfield, VA 22161 \\ Telephone 703-605-6000 (1-800-553-6847) \\ TDD 703-487-4639 \\ Fax 703-605-6900 \\ E-mail info@ntis.gov \\ Website http://www.ntis.gov/help/ordermethods.aspx
}

Reports are available to DOE employees, DOE contractors, Energy Technology Data Exchange representatives, and International Nuclear Information System representatives from the following source:

Office of Scientific and Technical Information

PO Box 62

Oak Ridge, TN 37831

Telephone 865-576-8401

Fax 865-576-5728

E-mail reports@osti.gov

Website http://www.osti.gov/contact.html

This report was prepared as an account of work sponsored by an agency of the United States Government. Neither the United States Government nor any agency thereof, nor any of their employees, makes any warranty, express or implied, or assumes any legal liability or responsibility for the accuracy, completeness, or usefulness of any information, apparatus, product, or process disclosed, or represents that its use would not infringe privately owned rights. Reference herein to any specific commercial product, process, or service by trade name, trademark, manufacturer, or otherwise, does not necessarily constitute or imply its endorsement, recommendation, or favoring by the United States Government or any agency thereof. The views and opinions of authors expressed herein do not necessarily state or reflect those of the United States Government or any agency thereof. 
US DOE Fuel Cycle Research and Development Advanced Fuels Campaign

INTERLABORATORY ROUND ROBIN TESTING OF SIC/SIC COMPOSITE TUBES

\author{
Gyanender Singh \\ Steve Gonczy \\ Edgar Lara-Curzio \\ Yutai Katoh
}

Date Published: August 19, 2016

Prepared by

OAK RIDGE NATIONAL LABORATORY

Oak Ridge, TN 37831-6283

managed by

UT-BATTELLE, LLC

for the

US DEPARTMENT OF ENERGY

under contract DE-AC05-00OR22725 



\section{Contents}

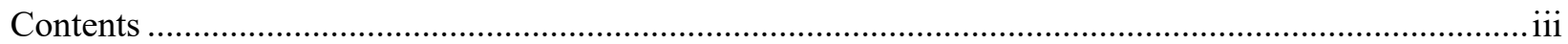

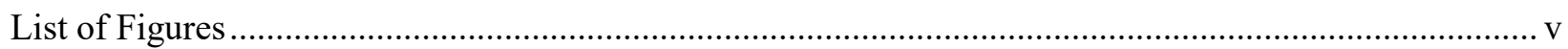

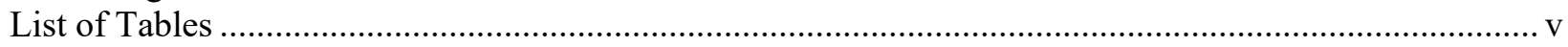

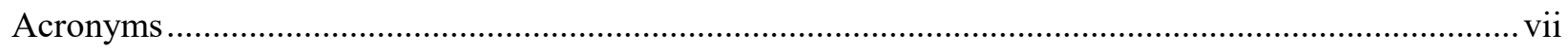

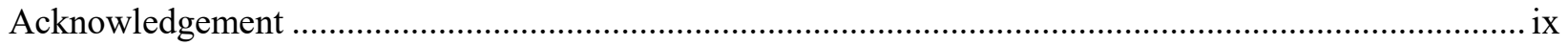

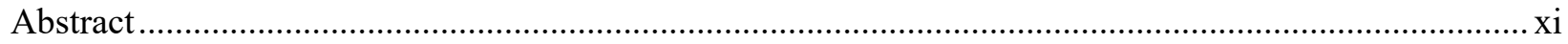

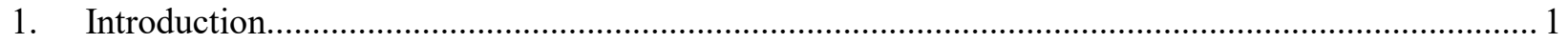

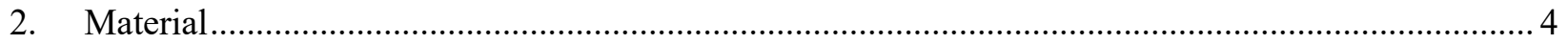

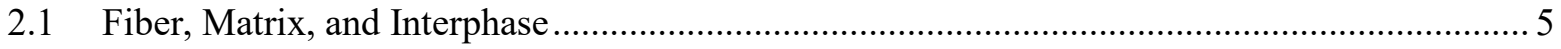

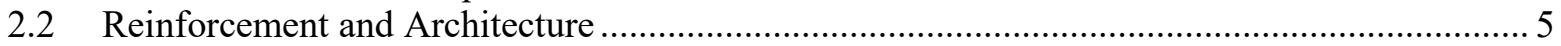

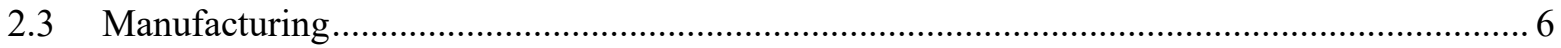

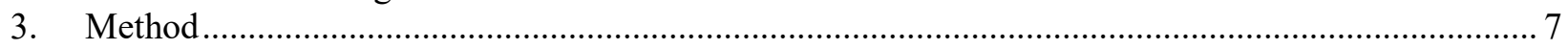

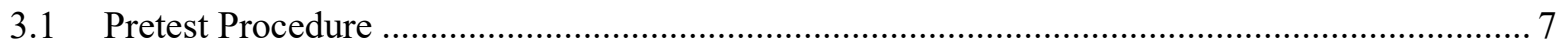

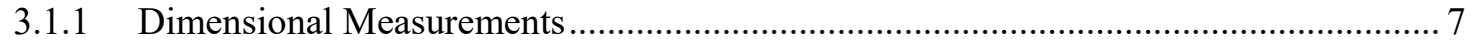

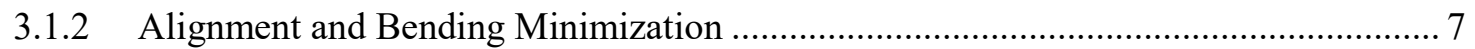



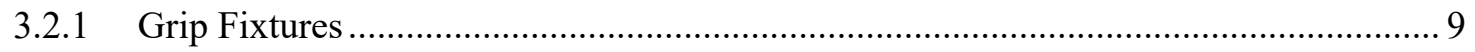

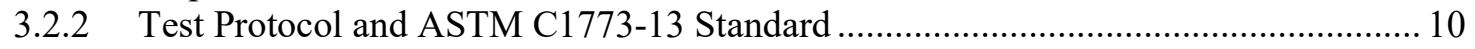

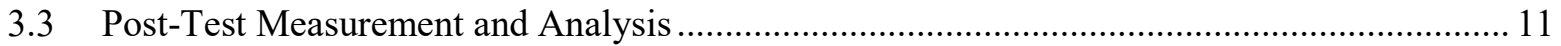

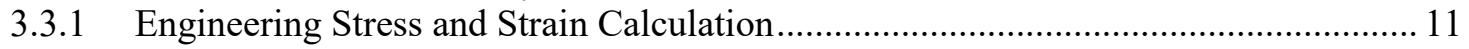

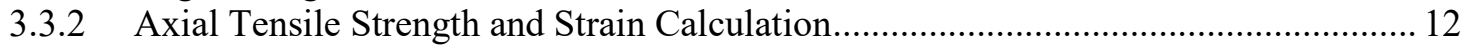

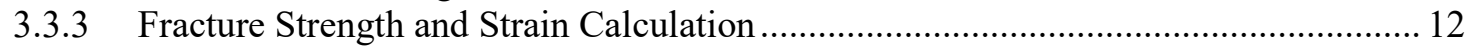

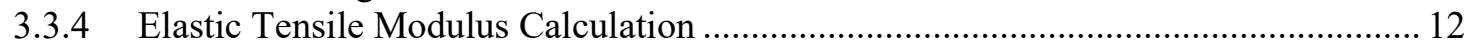

3.3.5 Proportional Limit Stress and Strain Calculation ...................................................... 13

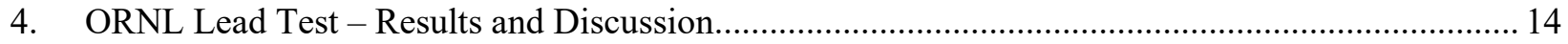

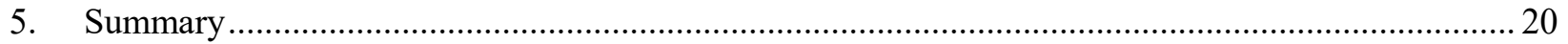

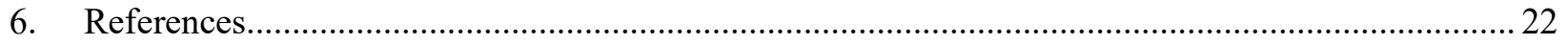

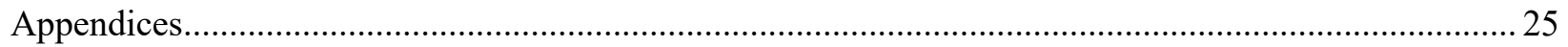

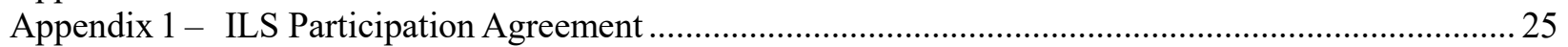

Appendix 2 - General Instructions for CMC Axial Tensile Tube Strength ILS Study ...........................26

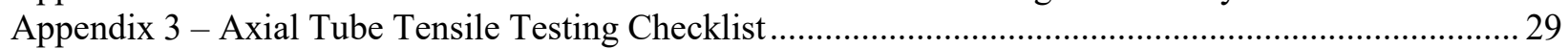

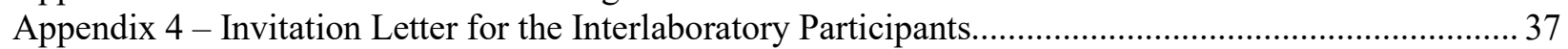

Appendix 5 - Task List for the Axial Tube Tensile (ATT) Test ILS Study............................................. 39

Appendix 6 - Axial Tensile Test Stress-Strain Curves for the SiC/SiC Specimens ................................. 40 


\section{List of Figures}

Figure 1: Cross-sectional planes of a $\mathrm{SiC} / \mathrm{SiC}$ tube as observed by optical microscopy (left) and

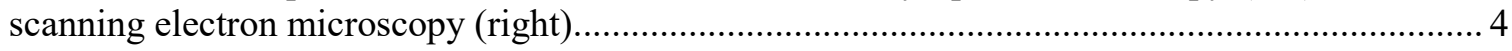

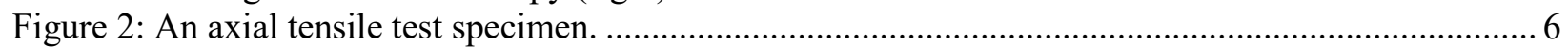

Figure 3: Sketch of an alignment specimen showing strain gage locations.......................................... 7

Figure 4: An alignment specimen used for aligning the top and bottom fixtures and minimize the

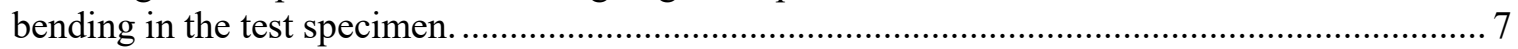

Figure 5: Swivel joints employed to minimize the bending which occurs due to irregular geometry

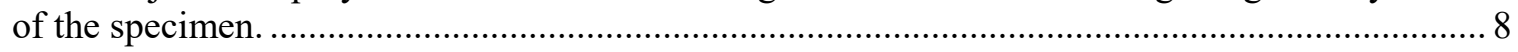

Figure 6: Fixture for gripping the specimen during the axial tensile tests............................................ 9

Figure 7: Annealed copper collets with tapered inner surface ...................................................... 9

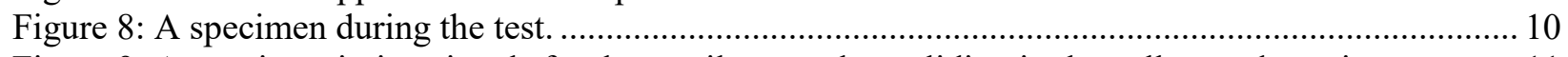

Figure 9: Acoustic emission signals for the tensile tests show sliding in the collets and specimen........... 11

Figure 10: Determination of ultimate tensile strength, Young's modulus and proportional limit stress from the stress-strain curve. Proportional limit stress is based on $0.01 \%$ strain offset.

Figure 11: Type-1 fixture (left) and a tested specimen along with the copper collets (right). Initial tests performed with Type-1 fixtures led to failure in the grip section......................................... 14

Figure 12: Copper collets and swivel joint (left) used in Type-2 fixtures (middle); the position of

collets in the fixture is shown schematically in the right figure. ..................................................
Figure 13: Type-2 fixtures enabled failure of the tube specimens in the gage section (left) but the non-linearity in the elastic regime of some of the stress-strain curves (right) indicated the possibility of bending in the specimens.

Figure 14: Swivel joints at top and bottom of the Type-3 fixture (left) removed bending from the specimen; a typical stress-strain curve for the specimens tested with this fixture........................ 16

Figure 15: Young's modulus of $\mathrm{SiC} / \mathrm{SiC}$ composite determined through the ORNL lead test................... 17

Figure 16: Ultimate tensile strength of $\mathrm{SiC} / \mathrm{SiC}$ composite determined through the ORNL lead test.

Figure 17: Proportional limit stress of $\mathrm{SiC} / \mathrm{SiC}$ composite determined through the ORNL lead test.

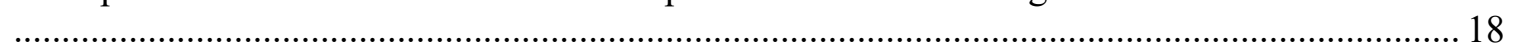

Figure 18: Strain at failure of $\mathrm{SiC} / \mathrm{SiC}$ composite determined through the ORNL lead test. ................... 19

Figure 19: Strain at proportional limit stress (PLS) of $\mathrm{SiC} / \mathrm{SiC}$ composite determined through the

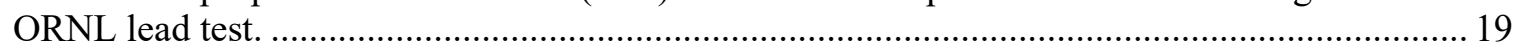

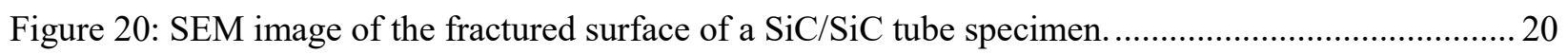

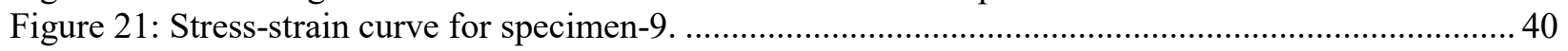

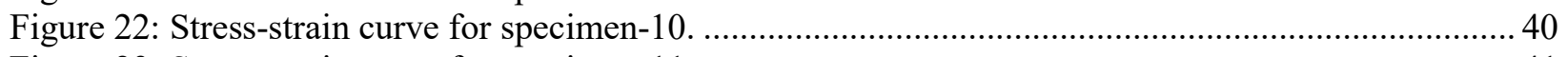

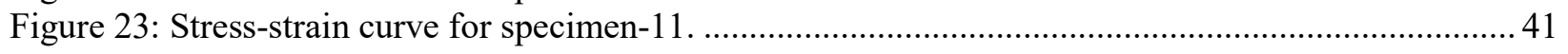

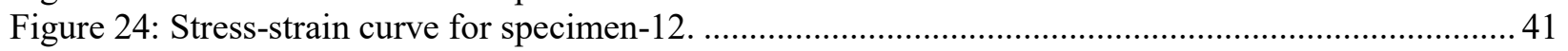

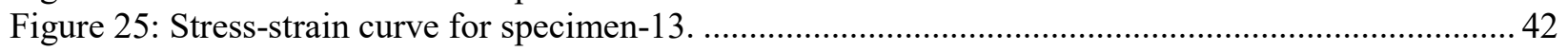

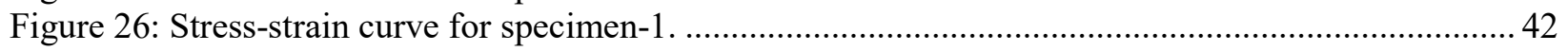

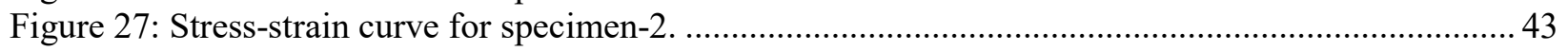

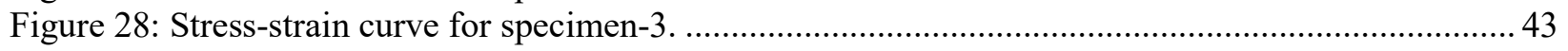

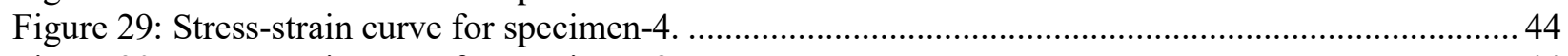

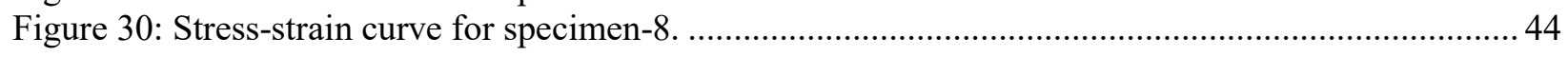

\section{List of Tables}

Table 1: Typical properties of $\mathrm{SiC} / \mathrm{SiC}$ composites (plane, orthotropic) at room temperature. Source [12]

Table 2: Mechanical properties of $\mathrm{SiC} / \mathrm{SiC}$ tubes determined through the ORNL lead test*................... 17

Table 3: Current list of committed participants to the interlaboratory round robin testing. ......................2 21 


\section{Acronyms}

$\begin{array}{ll}\text { ATF } & \text { Accident-tolerant fuel } \\ \text { AFC } & \text { Advanced Fuels Campaign } \\ \text { DOE-NE } & \text { US Department of Energy Office of Nuclear Energy } \\ \text { FCRD } & \text { Fuel Cycle Research and Development } \\ \text { RT } & \text { Room temperature } \\ \text { LWR } & \text { Light water reactor } \\ \text { ORNL } & \text { Oak Ridge National Laboratory } \\ \text { PWR } & \text { Pressurized water reactor } \\ \text { SiC } & \text { Silicon Carbide } \\ \text { UTS } & \text { Ultimate tensile strength } \\ \text { PLS } & \text { Proportional limit stress } \\ \text { SiC/SiC } & \text { Silicon carbide fiber-reinforced silicon carbide matrix composite } \\ \text { OD } & \text { Outer diameter } \\ \text { ID } & \text { Inner diameter } \\ \text { ASTM } & \text { American Society for Testing and Materials } \\ \text { CFCC } & \text { Continuous fiber-reinforced ceramic matrix composite } \\ \text { ILS } & \text { Interlaboratory study } \\ \text { AE } & \text { Acoustic emission }\end{array}$




\section{Acknowledgement}

The authors would like to thank Charles Shane Hawkins, Don Erdman, Rick Lowden and Chris Stevens from ORNL for their technical support for the mechanical testing and Christian Deck from General Atomics for the work on specimen design and Takaaki Koyanagi for the technical review of this report. Research work presented herein was conducted in the Mechanical Properties \& Mechanics Group and Low Activation Materials Development and Analysis (LAMDA) facility of Materials Science and Technology Division at Oak Ridge National Laboratory. Research sponsored by the Advanced Fuels Campaign of the Fuel Cycle R\&D program, Office of Nuclear Energy, US Department of Energy, under contract DE-AC0500OR22725 with UT-Battelle, LLC. 


\begin{abstract}
With the objective to develop accident tolerant fuel-clad systems for light water reactors, extensive research and development work is being conducted at different governmental, university and industrial labs. Continuous $\mathrm{SiC}$ fiber-reinforced $\mathrm{SiC}$ matrix $(\mathrm{SiC} / \mathrm{SiC})$ composites is one of the leading candidate materials for replacing the traditional $\mathrm{Zr}$ alloy cladding due to its high temperature stability, chemical inertness and stability under neutron irradiation. A rich database on the statistics of the mechanical properties of $\mathrm{SiC} / \mathrm{SiC}$ composite is much needed to carry out the feasibility studies as well as rigorous analysis of the material's behavior under normal and off-normal reactor conditions. In addition to the properties database, test standards, which ensure the unbiased characterization of the material, are needed. The mechanical properties database, particularly for tubular $\mathrm{SiC} / \mathrm{SiC}$ specimens, is limited and standardized test methods are still under development. The current work focuses on filling these gaps through an interlaboratory round robin testing program of $\mathrm{SiC} / \mathrm{SiC}$ composite tube specimen involving several organizations from academia, government laboratories and industry. The difficulties and issues in the testing were identified and addressed through the ORNL lead test. This report summarizes the current status and forward planning on the interlaboratory study.
\end{abstract}




\section{INTRODUCTION}

\section{Background and Objectives}

Silicon carbide ( $\mathrm{SiC}$ ) fiber-reinforced $\mathrm{SiC}$ matrix composites ( $\mathrm{SiC} / \mathrm{SiC}$ composites) offer a set of properties that make these materials highly suitable for several applications. Like ceramics $\mathrm{SiC} / \mathrm{SiC}$ composites maintain their mechanical properties and chemical inertness even at temperatures beyond the upper limit for typical metallic superalloys. These materials have high specific strength and show reasonable fracture toughness. Some of the applications for which $\mathrm{SiC} / \mathrm{SiC}$ composites are being considered include heat exchangers, reformers, reactors and filters in chemical industry, preheaters, recuperators and radiation tubes in heat transfer systems, space vehicles, furnace components combustion and turbine sections of gas turbine engines and nuclear reactors.

The Fukushima Daiichi nuclear power plant accident led to wide spread safety concerns over existing nuclear reactors around the globe. In efforts to enhance the safety of nuclear power plants extensive research and development work on enhancing the accident tolerance of fuel-cladding systems is being conducted $[1,2]$. Because of the stability of $\mathrm{SiC} / \mathrm{SiC}$ composites under neutron irradiation conditions, low activation and other properties as mentioned above, $\mathrm{SiC} / \mathrm{SiC}$ is a promising candidate material for the accident tolerant fuel cladding systems in light water reactors (LWR) [3, 4]. It should be noted here that the stability under irradiation is a unique property of $\mathrm{SiC} / \mathrm{SiC}$ composite in the class of composite materials and is not offered by other composites including carbon fiber based composites. Besides application in LWRs, $\mathrm{SiC} / \mathrm{SiC}$ composite has potential applications in other energy systems such as Very High Temperature Reactor (VHTR) [5, 6], gas-cooled fast reactor (GFR) [7], molten salt reactor (MSR), sodium fast reactor (SFR), and fusion reactors $[8,9]$. Although $\mathrm{SiC} / \mathrm{SiC}$ composites are manufactured in the forms of chopped fiber composites, particulate-reinforced composites and continuous fiber composites, only continuous fiber $\mathrm{SiC} / \mathrm{SiC}$ composites are suitable for fuel cladding fabrication.

Although $\mathrm{SiC} / \mathrm{SiC}$ composites are promising materials for cladding and core components of nuclear reactors, several considerations and critical feasibility issues need to be addressed before the material can be deployed and commercialized [10]. A "qualified" database of properties of $\mathrm{SiC} / \mathrm{SiC}$ composite will be needed for performing rigorous experimental and numerical studies to determine the viability of the material for specific applications. In general "qualified" database is one which is generated using procedures which comply with standards associated with the design code of the component of interest. In the absence of database the studies for assessment of the material either cannot be carried out or the results of the studies cannot be interpreted and applied with confidence, leading to designs with high safety margins. Besides, designer cannot use a material directly in new designs but has to 1) provide evidence that the material complies with the code requirement and 2) obtain permission to use that material in design [11]. Thus, lack of comprehensive database can significantly hamper the development of the technology and can negatively affects the material development.

The current database of mechanical properties for nuclear grade $\mathrm{SiC} / \mathrm{SiC}$ composite is limited. Although various properties of nuclear grade $\mathrm{SiC} / \mathrm{SiC}$ composites were previously measured, tube specimens were not used in these studies [12]. Most of the studies utilized rectangular bars and disc specimens for thermo-mechanical and physical property evaluations. The ASTM standard test methods for axial tensile test (ASTM C1773-13) and hoop tensile test (ASTM C1819-15) of continuous-fiber reinforced ceramic composite tubes have been developed and become available only recently. However, these ASTM standards lack the precision and bias statements which convey important information to the users of the ASTM standard about the practical applicability of their test results. In other words, these standards are still under development.

The current work described in this report aims to fill these gaps in the development process of $\mathrm{SiC}$ nuclear fuel cladding technology. An interlaboratory round robin study on $\mathrm{SiC} / \mathrm{SiC}$ tubes is planned and being conducted involving several different laboratories from government institutions, academia and industry. This interlaboratory study will serve multiple objectives: 1) Expand the limited database of mechanical properties of $\mathrm{SiC} / \mathrm{SiC}$ composite and 2) Develop precision and bias statement for the ASTM 
C1773 Standard Test Method (Monotonic Axial Tensile Behavior of Continuous Fiber-Reinforced Advanced Ceramic Tubular Test Specimens at Ambient Temperature).

The following section provides details on the significance of the precision and bias statements of a test standard and how the interlaboratory round robin study will establish these statements. Section 2 describes the $\mathrm{SiC} / \mathrm{SiC}$ composite that is being used for the interlaboratory study. This section also provides information about the typical physical and mechanical properties for this material. Section 3 describes the details of the procedure for testing the specimens: pretest procedure, testing the specimen and the analysis procedure following the test. Section 4 describes the ORNL lead test which was performed with the objective of determining and addressing the issues that may arise during the testing of the tubular specimen. The major modifications in the design of the fixtures and the test specimen, which were performed during the ORNL lead test, are described in this section. Section 5 summarizes the work conducted so far and provides details on the current status and next steps to complete the interlaboratory study.

This report fulfills fiscal year 2016 (FY16) milestone number M2FT-16OR020202111 within Work Package FY16-16OR02020211 at ORNL for the DOE-NE Advanced Fuels Campaign.

\section{Precision \& Bias of a Test Standard}

This section describes precision and bias of a test standard and its significance from the perspective of a user of the test standard.

When specimens of a presumably identical material are tested under presumably identical conditions, their test results are in general not identical. Apart from the random variation in the material itself, operators, test equipment and environmental factors also contribute to the variation in the test results. If the tests are conducted over a larger span of time then the variation in the results is usually greater. The differences in calibration of the equipment can contribute to variability in the test results. Thus, there are several factors which lead to variability in the results and these factors vary from within the laboratory and also from laboratory to laboratory. It is important to take into account the variability caused due to these factors before the test data can be used for any particular application. For instance, if two materials A and $\mathrm{B}$ are compared for tensile strength and the values obtained for material A are higher, then it may be not because material A is stronger than material $\mathrm{B}$ but it could be due to the factors mentioned above.

The closeness of the test result to the accepted reference value is generally termed as accuracy. The standard test methods report this accuracy in terms of precision and bias. Precision of a standard test method is expressed as the repeatability and reproducibility of the test results. Repeatability refers to the accuracy of the results when the factors mentioned above are kept constant or their minimal variation is allowed. Reproducibility refers to accuracy of the results when these factors are allowed to vary from one laboratory to another laboratory while each laboratory maintains minimal variation in these factors. Thus, precision of a test method provides an estimate of the variation the user of the test method can expect, which in turn reflects the utility of the standard test method.

Currently few standards exist for mechanical testing of continuous fiber-reinforced ceramic matrix composites (CFCC) at ambient temperature. Of these standards American Society for Testing and Materials (ASTM) standards are widely accepted and used. This is partly because the ASTM standards include precision and bias statements which are lacking in other standardized test methods. However, the current ASTM standards on mechanical testing of CFCCs (ASTM C1773-13) do not include these statements due to the nature of the material and lack of wide data base on a variety of advanced ceramic composite tubes tested in tension. The work presented herein focuses on determining the precision and bias for this test standard.

\section{Overview of the Interlaboratory Round Robin Study}

The above-mentioned objectives will be accomplished through the interlaboratory round robin study which will be conducted according to the ASTM E691-09 standard: Standard Practice for Conducting 
an Interlaboratory Study to Determine the Precision of a Test Method. Primary mechanical properties of interest are axial elastic modulus, proportional limit stress and the corresponding strain, ultimate tensile strength and the corresponding strain. At the first stage of this interlaboratory study ORNL lead test has been performed to identify the difficulties and issues with the testing of the $\mathrm{SiC} / \mathrm{SiC}$ tube specimens. These issues were addressed during the lead test stage and the final version of the test protocol was prepared. The objective of the test protocol is to help the interlaboratory participants to rigorously implement the ASTM C1773-13 requirements and fulfill the specific requirements pertaining to the testing of the $\mathrm{SiC} / \mathrm{SiC}$ tube specimens employed in this study. After the completion of the ORNL lead test, the specimens, fixtures and other parts for testing are being distributed to the interlaboratory study participants. The participanting laboratories will independently test the specimens according to the test protocol and report the test results in a set duration of time. The test results will be discussed with the ASTM Committee C28 on Advanced Ceramics and Subcommittee C28.07 on Ceramic Matrix Composites during the annual meeting. Precision and bias statements based on the test results will be recommended to the committees. Test results will be circulated among scientific community through journal publication. 


\section{MATERIAL}

\section{Nuclear Grade SiC/SiC Composite}

The $\mathrm{SiC} / \mathrm{SiC}$ ceramic matrix composite used for the work presented herein comprises of chemical vapor infiltration (CVI) SiC matrix and Hi-Nicalon Type $\mathrm{S}$ fibers with pyrocarbon interphase. This material is the first generation nuclear grade $\mathrm{SiC} / \mathrm{SiC}$ composite. The strength degradation by irradiation was found only at high doses. The swelling and change in the thermal conductivity of the $\mathrm{SiC} / \mathrm{SiC}$ composite saturates at about $1 \mathrm{dpa}$ [13]. The properties of the nuclear grade $\mathrm{SiC} / \mathrm{SiC}$ composites can be found elsewhere [12]. Note that the properties of the tube specimens are not available in reference [12]. The typical properties of $\mathrm{SiC} / \mathrm{SiC}$ composite for flat, orthotropic specimens are listed in Table 1. Figure 1 shows the porous structure and non-circularity in the cross-section of a $\mathrm{SiC} / \mathrm{SiC}$ tube specimen.

Table 1: Typical properties of $\mathrm{SiC} / \mathrm{SiC}$ composites (plane, orthotropic) at room temperature. Source [12]

\begin{tabular}{|c|c|}
\hline Property & Value \\
\hline Bulk density & $2.5-2.7 \mathrm{~g} / \mathrm{cm}^{3}$ \\
\hline Porosity & $10-20 \%$ \\
\hline Thermal conductivity & $8.5 \pm 2 \mathrm{~W} / \mathrm{mK}$ (through-thickness) \\
\hline Young's modulus & $200-280 \mathrm{GPa}$ (in-plane) \\
\hline Poisson's ratio & $\sim .13$ for $0^{\circ} / 90^{\circ}, \sim 0.25$ for $\pm 45^{\circ}$ (in plane) \\
\hline Proportional limit stress & $90-120 \mathrm{MPa}$ (in plane) \\
\hline Ultimate tensile strength & $250-350 \mathrm{MPa}$ (in plane, $0^{\circ} / 90^{\circ}$ ) \\
\hline
\end{tabular}

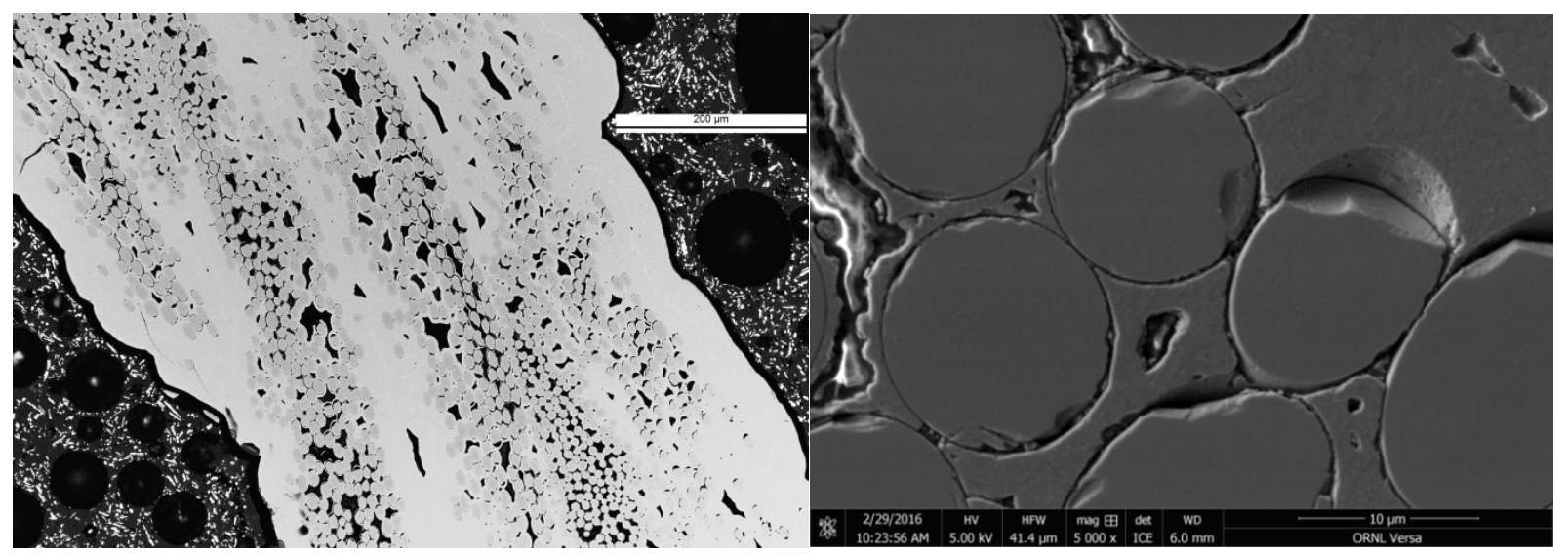

Figure 1: Cross-sectional planes of a $\mathrm{SiC} / \mathrm{SiC}$ tube as observed by optical microscopy (left) and scanning electron microscopy (right). 


\subsection{FIBER, MATRIX, AND INTERPHASE}

\section{Fiber}

The $\mathrm{SiC} / \mathrm{SiC}$ composite used for this work contains Hi-Nicalon ${ }^{\mathrm{TM}}$ Type $\mathrm{S}$ fibers. These fibers are near stoichiometric (manufacturer-claimed $\mathrm{C} / \mathrm{Si}$ atomic ratio of $\sim 1.05$ ), stable under neutron irradiation, show limited irradiation creep [14] and can maintain thermal creep strength up to $1400^{\circ} \mathrm{C}$ [15]. The fibers have a typical chemical composition of $\mathrm{Si}: \mathrm{C}: \mathrm{O}$ as $69: 31: 0.2 \mathrm{wt} \%$ and the tensile strength and tensile modulus are $2.6 \mathrm{GPa}$ and $420 \mathrm{GPa}$, respectively $[16,17]$. The typical filament diameter and density are $11 \mu$ and $3.10 \mathrm{~g} / \mathrm{cc}$. These fibers are commercially produced by NGS Advanced Fibers Co. (Toyama, Japan). Extensive research efforts on the development of these fibers are presented in reference [18].

\section{Interphase}

A monolayer of pyrocarbon (PyC) forms the interphase between the fiber and matrix in the $\mathrm{SiC} / \mathrm{SiC}$ composite used for this work. Interphase plays an important role in imparting mechanical properties to the composite: interphase material is more compliant than both fiber and matrix, and it deflects cracks propagating through the matrix, thus preventing fiber cracking. Interphase imparts pseudo ductility to the composite material by allowing the fibers to debond and slide, and bridge matrix cracks. For nuclear applications only $\mathrm{PyC}$ or $\mathrm{PyC} / \mathrm{SiC}$ are suitable choices.

\section{Matrix}

The composite material used in this interlaboratory study has high-purity SiC matrix. Similarly to the fibers, only near stoichiometric matrices with high crystallinity and a minimum of secondary phases are stable in irradiation environments. Of the several techniques available to densify the matrix, CVI has been found to produce matrix of such quality [19]. Besides, Nano-Infiltration and Transient Eutectic-Phase (NITE) process has also been found to produce $\mathrm{SiC} / \mathrm{SiC}$ composites that are stable under irradiation [2022]. The CVI process was employed to prepare the $\mathrm{SiC} / \mathrm{SiC}$ specimens used in this work. This process is described briefly in the section 2.3 .

\subsection{REINFORCEMENT AND ARCHITECTURE}

Fibers are typically produced as single tows. These tows are then weaved or knitted to form a variety of fabric types, including preforms. Preforms are a type of fabric form suited for a particular application in terms of shape, mechanical and structural requirements. Fiber preforms for the test material were fabricated using triaxial braiding. This weaving style allows the fabric to conform to complex shapes and retains balance on both side of the fabric. The fiber bundles were stacked in $\pm 55^{\circ}$ orientation with some fiber bundles at $0^{\circ}$ direction for axial reinforcement. This type of stacking imparts symmetric in-plane strength to the material.

An axial tensile test specimen is shown in Figure 2. The specimens are 6 inches in length with $8^{\circ}$ tapered shoulders. The nominal wall thickness, outer diameter and gage section are $0.7 \mathrm{~mm}, 10 \mathrm{~mm}$ and 70 $\mathrm{mm}$ respectively. 


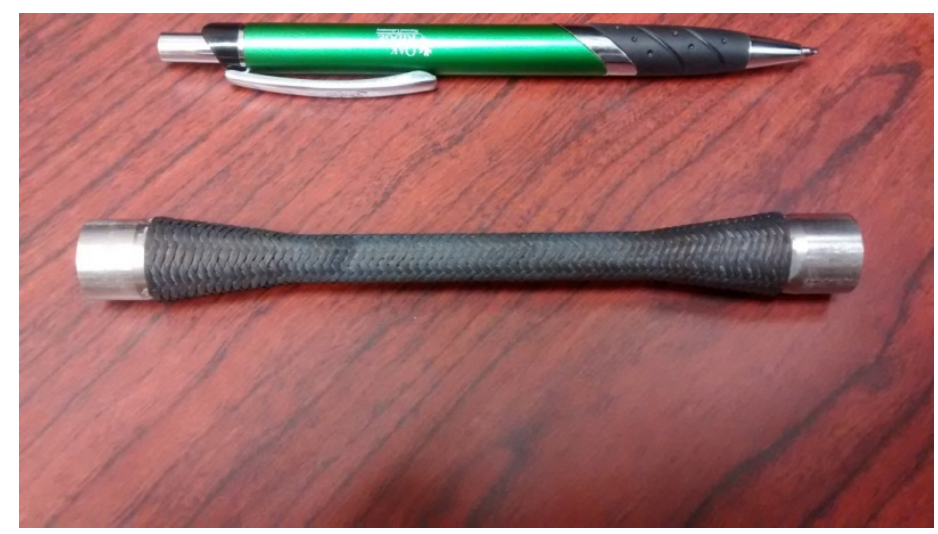

Figure 2: An axial tensile test specimen.

\subsection{MANUFACTURING}

There are several techniques for densifying the ceramic matrix between the fibers of a $\mathrm{SiC} / \mathrm{SiC}$ composite: 1) CVI, 2) polymer impregnation \& pyrolysis (PIP), 3) liquid silicon infiltration (LSI, also known as melt infiltration $=$ MI or reaction sintering $=\mathrm{RS}$ ) and 4) impregnating the fiber with $\beta$ SiC based slurry followed by sintering at elevated temperature and pressure (such as NITE). The specimens used in for the current work were purchased from General Atomics, San Diego, CA. These specimens were prepared through the CVI technique. The CVI $[23,24]$ technique is currently the best known technique for number of reasons, particularly because of its ability to produce a $\mathrm{SiC}$ phase of high purity and crystallinity - a necessary requirement for the stability of the material under neutron irradiation [19]. The CVI process obviates the need for mechanical loads for densification and avoids damage to the fibers and interdiffusion of fibers and matrix.

The CVI technique is used to successively deposit the interphase, matrix and external coating on the fiber preform. The process is carried out in the temperature range of $900-1100^{\circ} \mathrm{C}$ and normal or reduced pressure. For depositing the matrix the CVI technique often employs a mixture of methyltrichlorosilane (MTS, $\mathrm{CH}_{3} \mathrm{SiCl}_{3}$ ) and hydrogen which acts as catalyst. The process parameters such as gas flow conditions, local concentration of the gaseous mixture affect the uniformity and purity of deposited $\mathrm{SiC}$. 


\section{METHOD}

\subsection{PRETEST PROCEDURE}

\subsubsection{Dimensional Measurements}

Geometric dimensions of all 57 test specimens were measured using the micrometers, callipers and radiography as part of the pretest inspections. The outer diameter of the tubes is measured at three different cross-sectional planes along the gage section. At each cross-section the measurements are made at $0^{\circ}, 60^{\circ}$ and $120^{\circ}$ radial angles to account for the variation in the dimensions with radial direction. The wall thickness is measured at the cross-section of both ends of the tested specimen at $0^{\circ}, 60^{\circ}$ and $120^{\circ}$ radial angles. The resolution of the measuring instrument should be at least $0.02 \mathrm{~mm}$. Ball-tipped micrometers are preferred as these micrometers reduce the potential of damage to the specimen. The inner diameter is calculated using the outer diameter and wall thickness. The test specimens are marked with an indelible marker to distinguish the top and bottom end of the specimens.

\subsubsection{Alignment and Bending Minimization}

There have been no studies conducted for studying the effect of bending in the specimen on the tensile strength distribution of CFCCs. However, for monolith advanced ceramics such studies have been conducted and it is concluded that the bending in the specimen should not exceed 5\% to keep the effects of bending on the strength distribution parameters negligible. Figures 3 and 4 show the alignment specimen used for performing the load train alignment. These alignment specimens employed strain gages with linear pattern (gage designation: C2A-06-125LW-350); the gages were obtained from Vishay Precision Group Inc. Because the $\mathrm{SiC} / \mathrm{SiC}$ composite and steel have nearly equal Young's modulus $(\approx 205 \mathrm{GPa})$, steel was selected as the material for the alignment specimens.

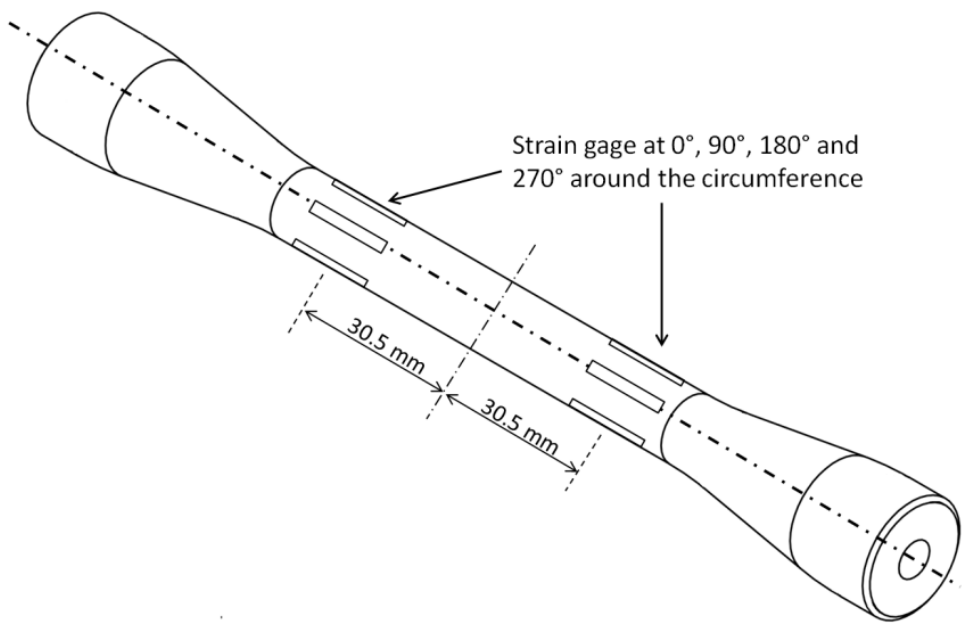

Figure 3: Sketch of an alignment specimen showing strain gage locations.

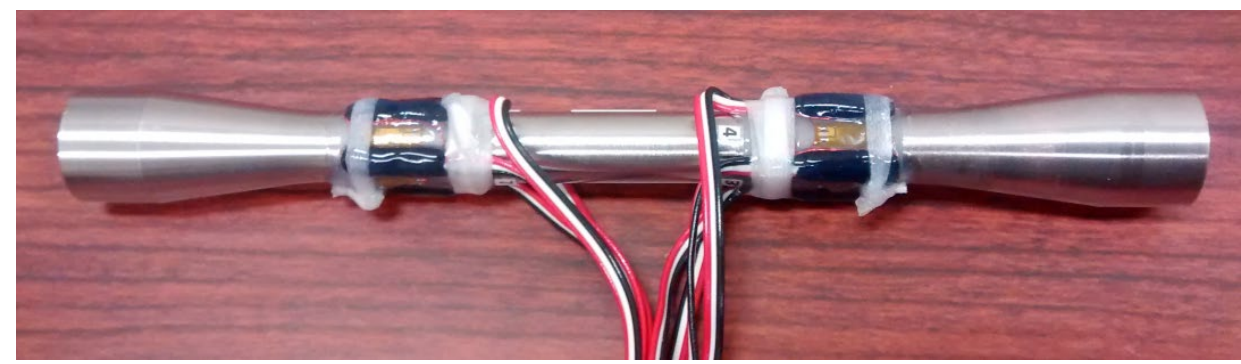

Figure 4: An alignment specimen used for aligning the top and bottom fixtures and minimize the bending in the test specimen. 
The bending in the specimen is calculated as:

$$
\begin{aligned}
& \text { Bending }(\%)=\frac{\varepsilon_{\mathrm{b}}}{\varepsilon_{\mathrm{o}}} \times 100 \\
& \varepsilon_{\mathrm{b}}=\left[\left(\frac{\varepsilon_{1}-\varepsilon_{3}}{2}\right)^{2}+\left(\frac{\varepsilon_{2}-\varepsilon_{4}}{2}\right)^{2}\right]^{1 / 2} \\
& \varepsilon_{\mathrm{o}}=\frac{\varepsilon_{1}+\varepsilon_{2}+\varepsilon_{3}+\varepsilon_{4}}{4}
\end{aligned}
$$

where $\varepsilon_{1}, \varepsilon_{2}, \varepsilon_{3}$ and $\varepsilon_{4}$ are the strains measured by the strain gages located at $0^{\circ}, 90^{\circ}, 180^{\circ}$ and $270^{\circ}$ respectively.

Unlike their monolith counterparts, which undergo catastrophic fracture, continuous fiberreinforced ceramic matrix composite (CFCC) accumulate damage during the loading process. Due to the gradual damage process, CFCCs exhibit a non-linear stress-strain behavior after the elastic limit. So, displacement controlled tests were employed to prevent "run away" condition - a rapid uncontrolled deformation and fracture. For the ORNL test a clip-on extensometer with gage length of $25 \mathrm{~mm}$ was employed to measure the strain. These tests were conducted using a MTS servohydraulic testing machine equipped with Model 646.10 hydraulic collet grips and $2500 \mathrm{lbf}$ load cell in ambient environment (temperature: $23^{\circ} \mathrm{C}$, humidity: $55 \%$ ). Test machine was set up for an initial cross-head position, zero load, and displacement mode and a displacement rate of $0.0127 \mathrm{~mm} / \mathrm{s}$. The specimens were preloaded to 7-9 $\mathrm{lb}$. Swivel joints were used to minimize bending in the specimen that is introduced by the deviations in the composite geometry from the nominal dimension.

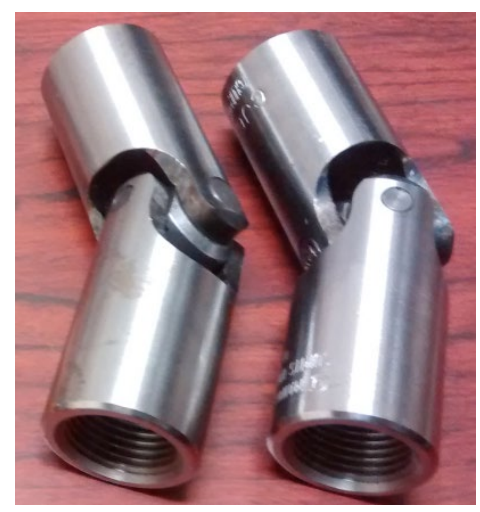

Figure 5: Swivel joints employed to minimize the bending which occurs due to irregular geometry of the specimen. 


\subsection{TEST PROCEDURE}

\subsubsection{Grip Fixtures}

There are two types of grip fixtures that are used for testing CFCC specimens with tube geometry: 1) Active grip fixtures and 2) Passive grip fixtures. Active grip fixtures require a direct application of the gripping force normal to the grip section of the test specimen. Split circular collets are commonly used for this purpose. The collets are pushed to the surface of the test specimen through mechanical, hydraulic or pneumatic action. Due to compressive force at the interface of the collets and the specimen, frictional force is generated which holds the specimen from moving axially. On the other hand passive grip fixtures do not require a direct application of gripping force; rather, the axial force applied by the test machine is employed to generated compressive force on the fixture either through adhesive bond or by mechanical links. For the current work passive grip fixtures were used.

Figure 6 shows the fixture employed for gripping the tube specimens. A specimen is directly in contact with the copper collets which served dual function of holding the specimen inside the fixture and also minimized bending in the specimen by deforming itself in response to the bending moment. The specimens had steel end plugs to prevent crushing in the grip sections as shown in Figure 2.
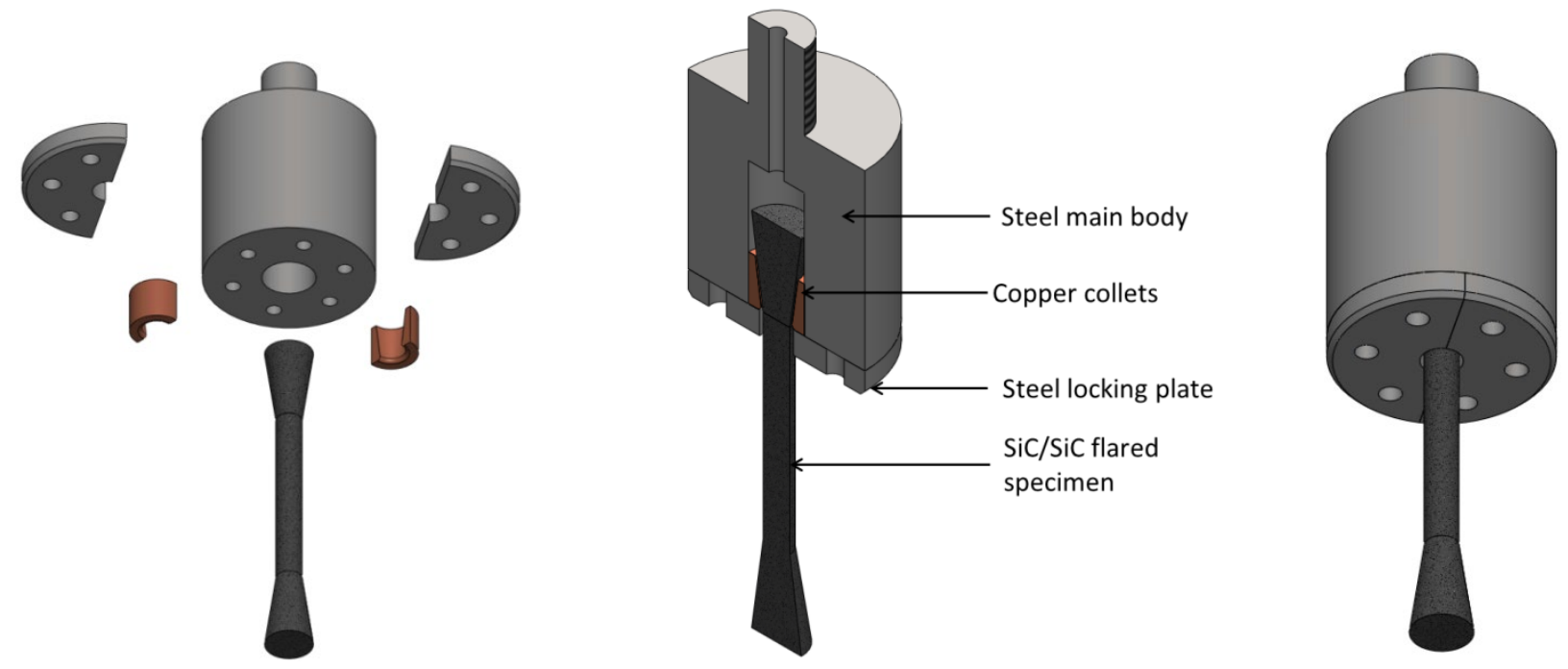

Figure 6: Fixture for gripping the specimen during the axial tensile tests.

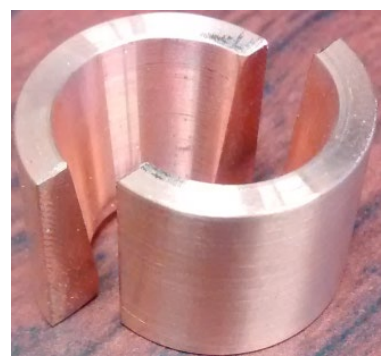

Figure 7: Annealed copper collets with tapered inner surface 


\subsubsection{Test Protocol and ASTM C1773-13 Standard}

The guidelines of standard test method ASTM C1773-13 (Standard Test Method for Monotonic Axial Tensile Behavior of Continuous Fiber-Reinforced Advanced Ceramic Tubular Test Specimens at Ambient Temperature) are followed to conduct the axial tensile test on $\mathrm{SiC} / \mathrm{SiC}$ tubular specimens. Figure 8 shows a specimen while being tested at ORNL. For the ORNL lead test acoustic emission (AE) technique was used to gain insight into the damage propagation process in the specimens during the tests and obtain other information about the tests which could have been missed by the direct observation.

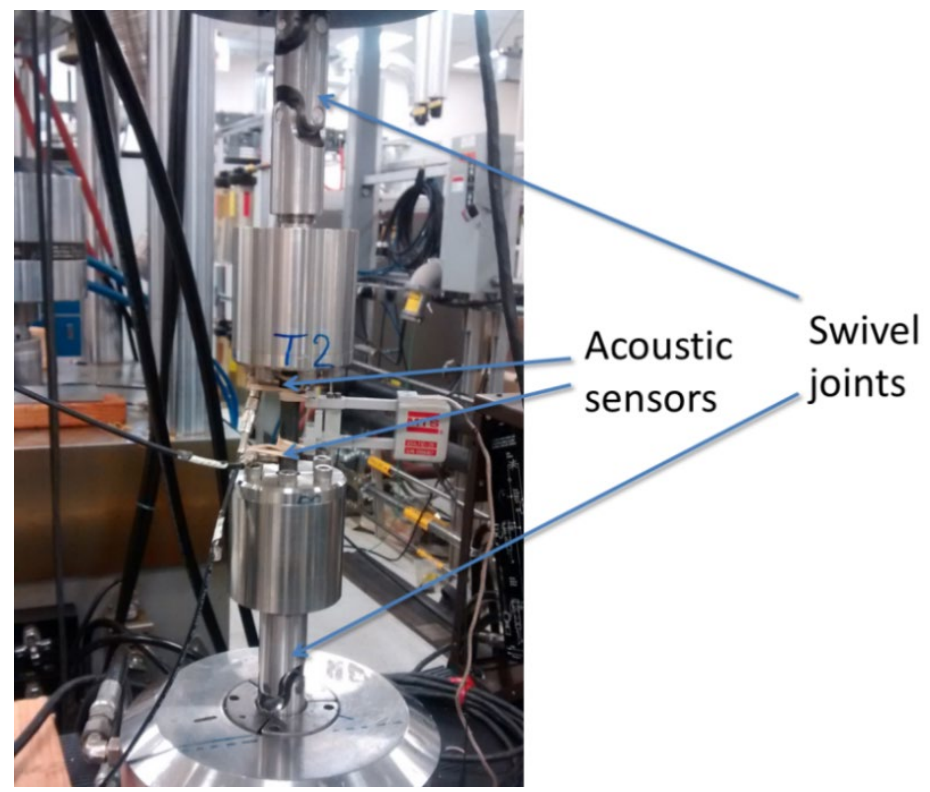

Figure 8: A specimen during the test.

The steps of the test procedure were established through the ORNL lead test ultimately to develop clarity and completeness of the testing. Difficulties in the testing of these tube specimens were identified and resolved. The geometry of the specimen was revised to avoid fracture in the grip section, leading to a more accurate determination of the tensile strength. The major revisions of the geometry included: a) chamfering of the steel plugs to reduce stress concentration b) strengthening the ends of the tubes with epoxy.

AE technique showed sliding of the collets and specimen due to slack up till $890 \mathrm{~N}$ load. Figure 9 shows AE signals generated due to sliding of the collets and specimen while being tested. To prevent damage in the specimen due to impulse load caused by the shift, a two-step loading rate was established: $0.0127 \mathrm{~mm} / \mathrm{s}$ for load below $890 \mathrm{~N}$ and $0.0635 \mathrm{~mm} / \mathrm{s}$ for load beyond $890 \mathrm{~N}$. All the detailed steps for conducting the tensile test were listed in the test protocol. The test protocol has been provided to the interlaboratory round robin participants to guide them in the testing and to maintain uniformity of testing parameters and conditions across the labs. 


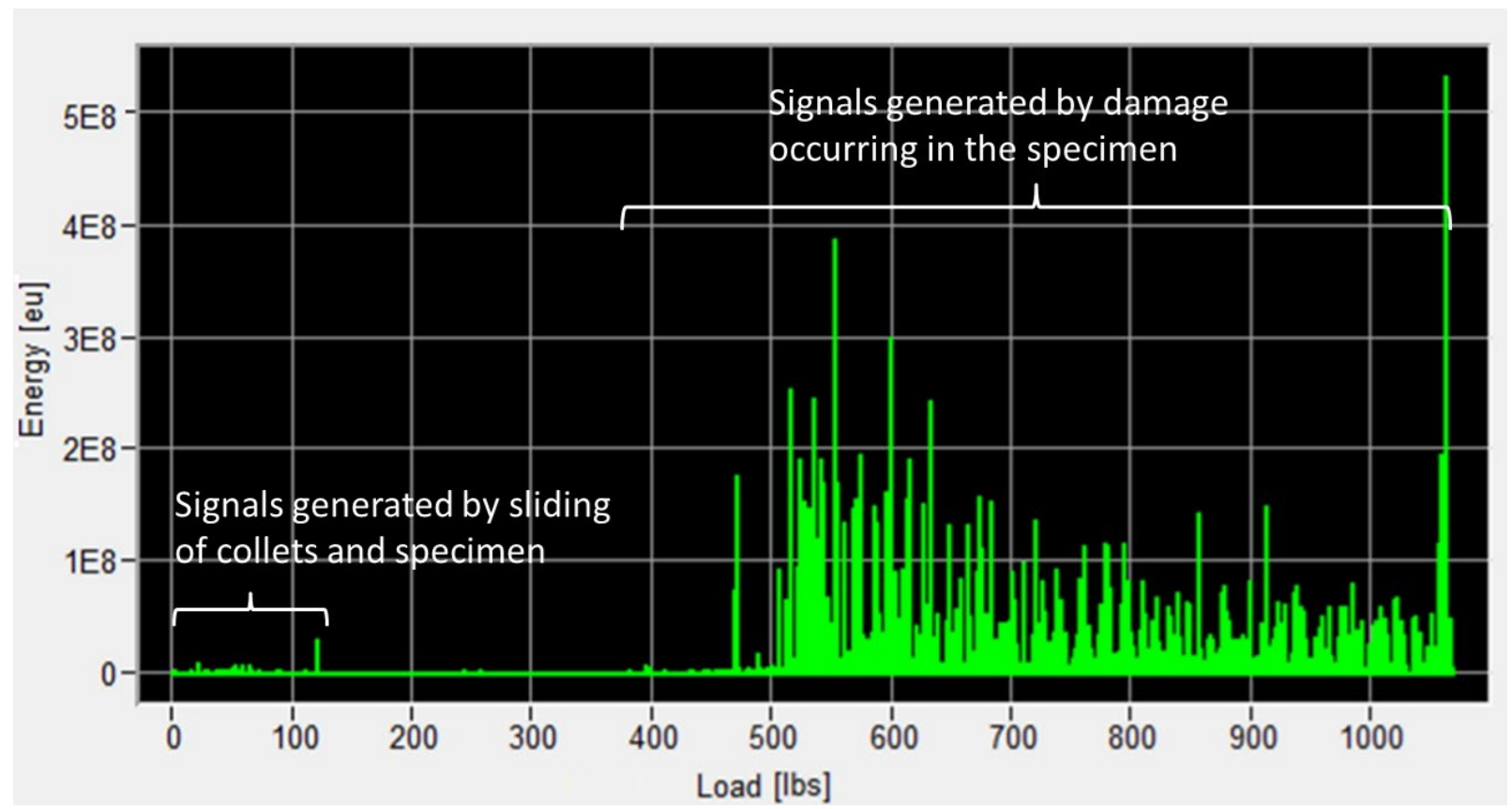

Figure 9: Acoustic emission signals for the tensile tests show sliding in the collets and specimen.

\subsection{POST-TEST MEASUREMENT AND ANALYSIS}

After the completion of the test, the gage section outer diameter (OD), inner diameter (ID) and fracture location are measured. The fracture locations relative to the midpoint of the gage section are measured. Using visual examination, optical microscopy and electron microscopy the fracture surfaces are analyzed to determine the mode and type of fracture.

\subsubsection{Engineering Stress and Strain Calculation}

The engineering stress is calculated as:

where:

$$
\sigma=\frac{\mathrm{P}}{\mathrm{A}}
$$

$\sigma$ : the engineering stress in units of $\mathrm{MPa}$,

$\mathrm{P}:$ the applied uniaxial tensile load in units of $\mathrm{N}$, and

A : the average original cross-section area of the tube specimen in units $\mathrm{of}_{\mathrm{mm}}^{2}$

The cross-sectional area A is calculated as:

$$
A=\frac{\pi\left(d_{o}^{2}-d_{i}^{2}\right)}{4}
$$

where

$d_{0}:$ the average outer diameter of the gage section in units of $\mathrm{mm}$

$d_{i}$ : the average inner diameter of the gage section in units of $\mathrm{mm}$

The engineering strain, measured by the extensometer, is calculated as: 


$$
\varepsilon_{\mathrm{yy}}=\frac{\mathrm{l}-\mathrm{l}_{\mathrm{o}}}{\mathrm{l}_{\mathrm{o}}}
$$

where

$\varepsilon_{y y}:$ the axial engineering strain (dimensionless)

$1:$ the extensometer gage length at any time in units of $\mathrm{mm}$

$1_{0} \quad: \quad$ the original extensometer gage length in units of $\mathrm{mm}$

\subsubsection{Axial Tensile Strength and Strain Calculation}

The axial tensile strength is calculated as:

$$
\mathrm{S}_{\mathrm{u}}=\frac{\mathrm{P}_{\max }}{\mathrm{A}}
$$

where:

$\mathrm{S}_{\mathrm{u}} \quad$ : the tensile strength in units of $\mathrm{MPa}$,

$\mathrm{P}_{\max }:$ the maximum force before failure in units of $\mathrm{N}$, and

A : the average original cross-section area of the tube specimen in units of $\mathrm{mm}^{2}$

The axial strain at tensile strength is measured as the axial engineering strain (equation 3 ) corresponding to the tensile strength measured during the test.

\subsubsection{Fracture Strength and Strain Calculation}

The axial fracture strength is calculated as:

$$
\mathrm{S}_{\mathrm{f}}=\frac{\mathrm{P}_{\text {fracture }}}{\mathrm{A}}
$$

where:

$\mathrm{S}_{\mathrm{f}} \quad: \quad$ the fracture strength in units of $\mathrm{MPa}$,

$P_{\text {fracture }}:$ the force corresponding to the fracture in units of $\mathrm{N}$, and

A : : the average original cross-section area of the tube specimen in units of $\mathrm{mm}^{2}$

The axial strain at fracture strength is measured as the axial engineering strain (equation 3 ) corresponding to the fracture strength measured during the test.

\subsubsection{Elastic Tensile Modulus Calculation}

The modulus of elasticity is determined from the slope of the line fitted to the linear portion of the stressstrain curve using linear regression. 


\subsubsection{Proportional Limit Stress and Strain Calculation}

The proportional limit stress (PLS), $\sigma_{0}$, can be defined in several ways: offset method, extension under force method and deviation from linearity method. The offset method is used for determining the PLS for the current work. For CFCC the failure strain is relatively lower than other materials for which a typical $0.5 \%$ offset strain is used to determine the PLS. So an alternate offset strain of $0.01 \%$ is employed. Figure 10 shows the procedure for determining the PLS using the offset strain of $0.01 \%$. A line is generated with its origin at zero stress and $0.01 \%$ strain, and running parallel to the linear portion of the stress-strain curve which was used to calculate the elastic modulus. The stress corresponding to the point where this line intersects the stress-strain curve is defined as the PLS. The strain at PLS is measured as the axial engineering strain (equation 3) corresponding to the PLS.

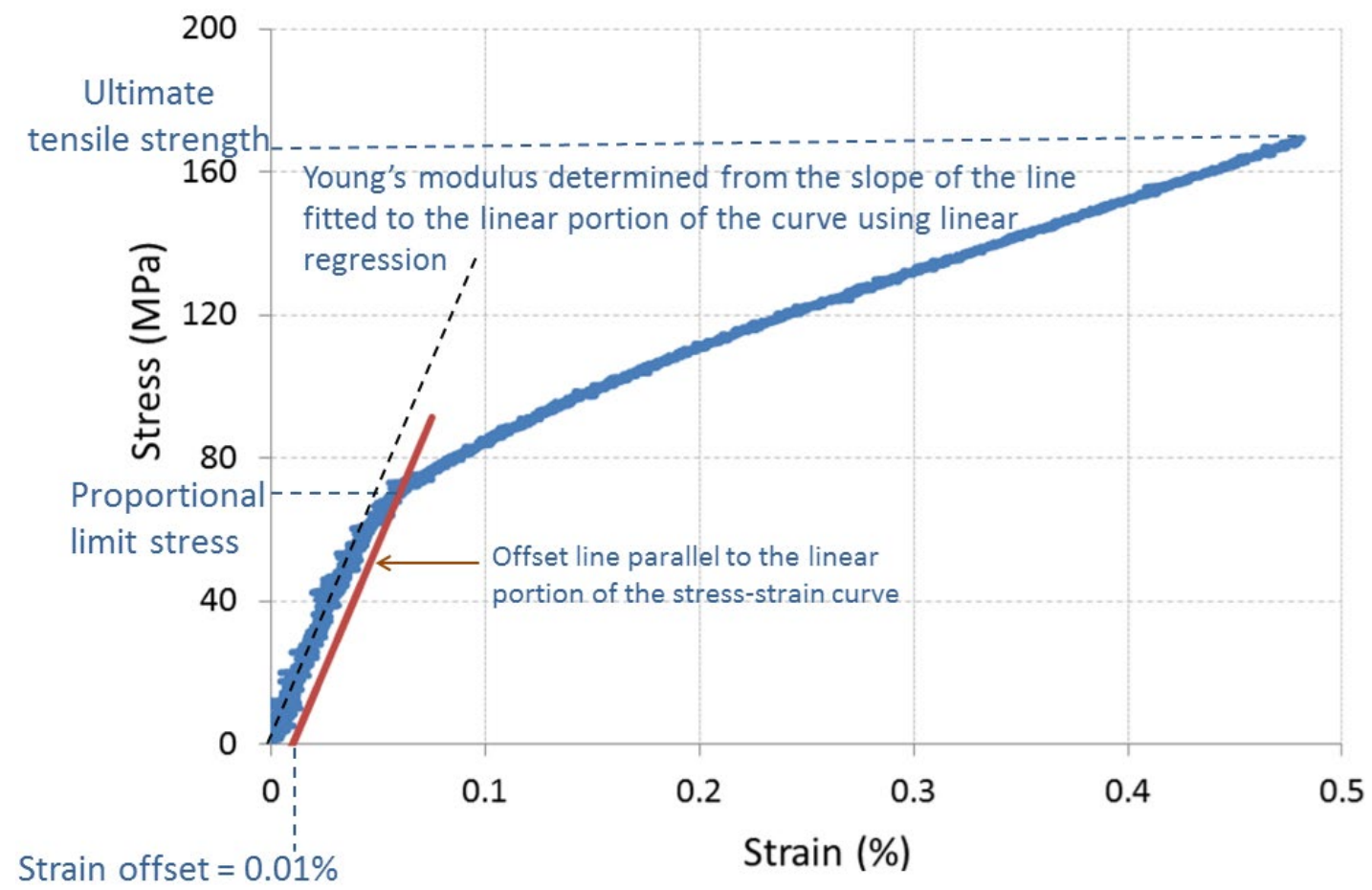

Figure 10: Determination of ultimate tensile strength, Young's modulus and proportional limit stress from the stress-strain curve. Proportional limit stress is based on $0.01 \%$ strain offset. 


\section{ORNL LEAD TEST - RESULTS AND DISCUSSION}

The ORNL lead test was performed with the objective of determining and addressing the potential problems that may arise during the interlaboratory round robin testing program. The initial tests were conducted using Type-1 fixtures shown in Figure 11. During these tests specimens failed at the grip section as shown in the Figure 11. It was inferred that the sharp edge of the steel insert could have induced a stress concentration at its contact region with the $\mathrm{SiC} / \mathrm{SiC}$ test specimen. Bending in the specimen was also identified as a potential cause of grip section failure. The load train is aligned using the alignment fixtures before the testing to minimize bending in the specimen. However, unlike metallic parts, parts made of composite materials have irregularities in their geometry. So, even after the alignment of fixtures, bending may persist in the specimens mounted on the fixtures. These initial tests employed copper collets which also served as fixtures. These fixtures were ineffective in removing bending in the specimens because of lack of self-aligning ability.

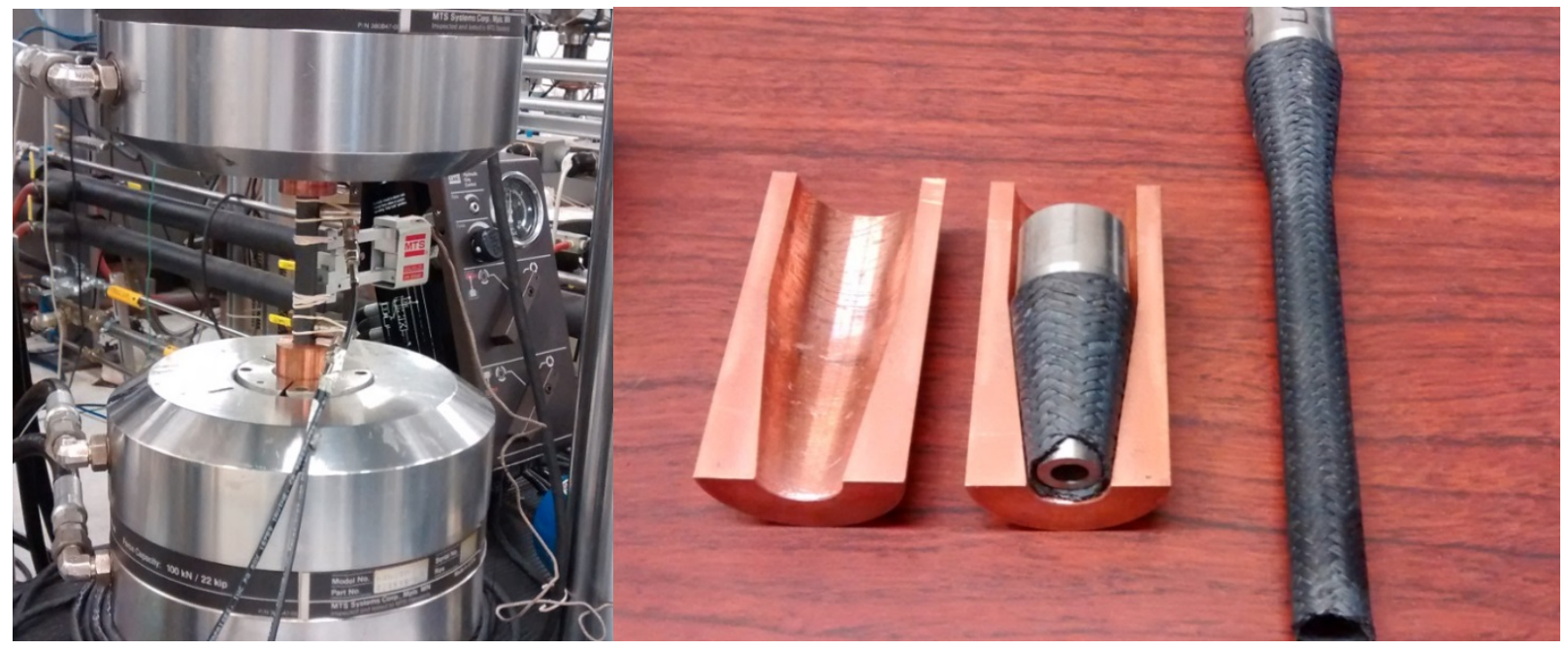

Figure 11: Type-1 fixture (left) and a tested specimen along with the copper collets (right). Initial tests performed with Type-1 fixtures led to failure in the grip section.

To reduce the stress concentration the steel plug was chamfered at its edge. Self-aligning fixtures (Type-2), shown in Figure 12 were employed with the intention to reduce the bending in the specimen. The two main features of these fixtures were the double swivel joint at the top end and the annealed copper collets that constrained the specimen inside the steel fixtures. The annealing heat treatment softened the copper collets, decreasing the hardness level from 140HV1 to 45HV1. The heat treatment involved temperature ramp up rate of $10^{\circ} \mathrm{C} / \mathrm{min}$ followed by constant temperature of $600^{\circ} \mathrm{C}$ for 1 hour and overnight cool down inside oven. Type-2 fixtures enabled failure in the gage section of the tube specimens. However, the stress-strain curves for the specimens tested with this fixture showed non-linearity in the elastic regime (see Figure 13), indicating the possibility that the fixtures were not completely successful in removing bending. 


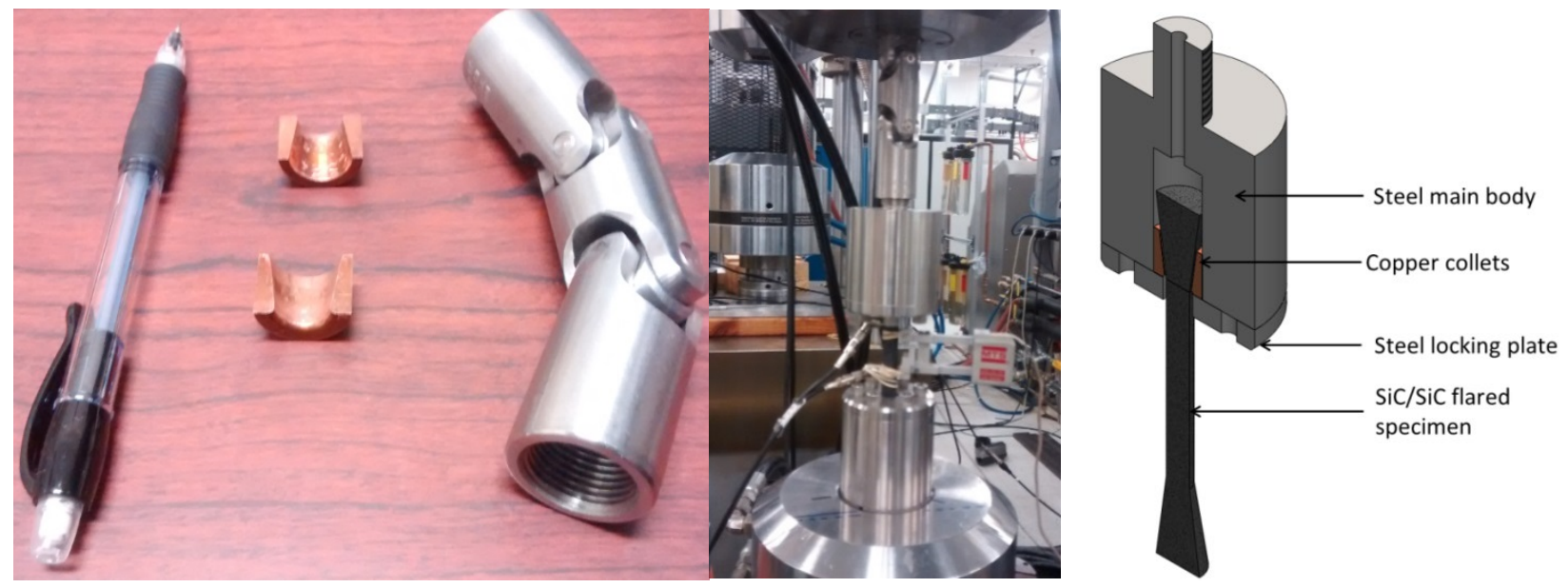

Figure 12: Copper collets and swivel joint (left) used in Type-2 fixtures (middle); the position of collets in the fixture is shown schematically in the right figure.
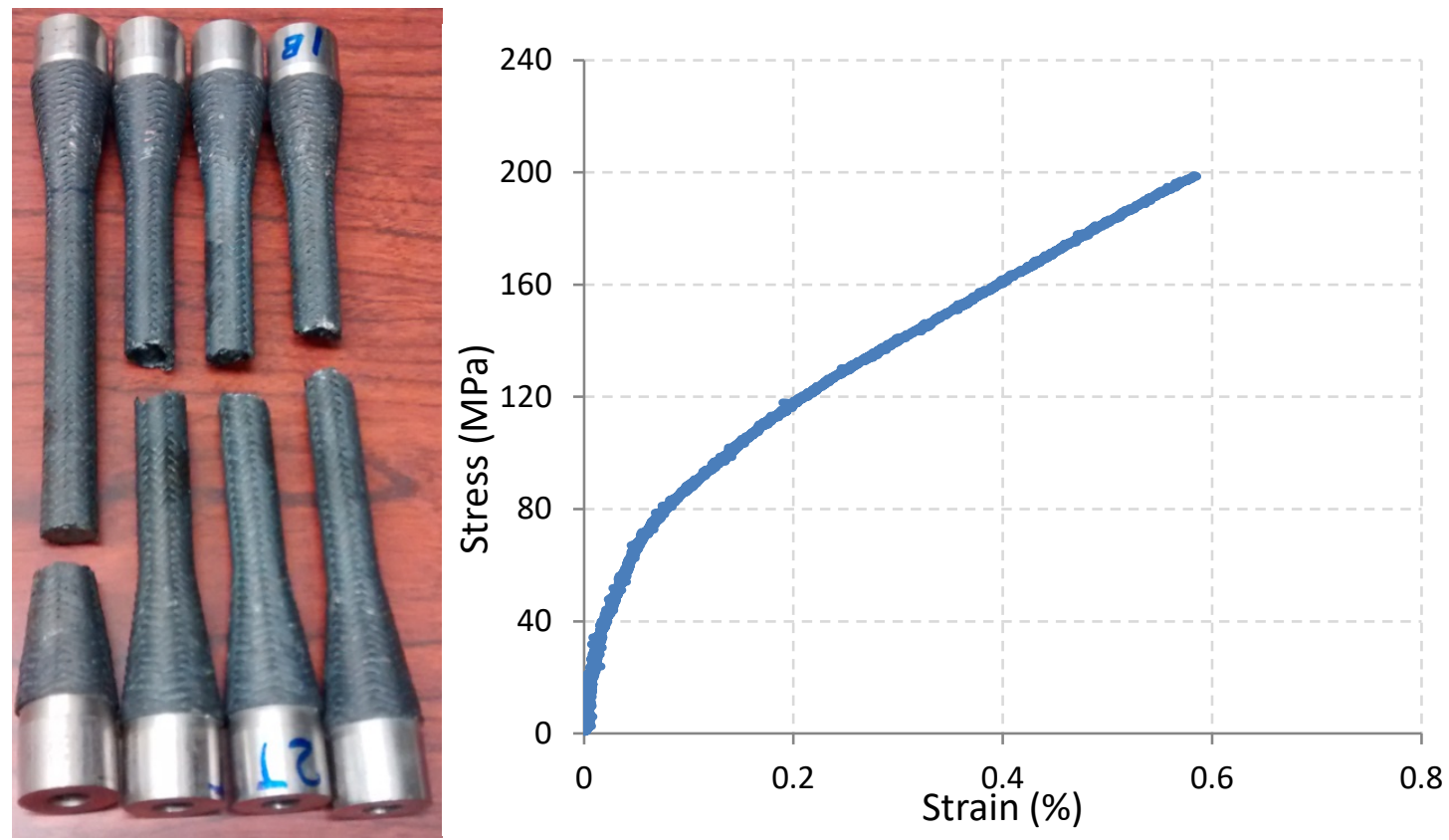

Figure 13: Type-2 fixtures enabled failure of the tube specimens in the gage section (left) but the nonlinearity in the elastic regime of some of the stress-strain curves (right) indicated the possibility of bending in the specimens.

Type-3 fixtures were employed to remove bending. These fixtures were similar to Type-2 fixtures except that a swivel joint was used to connect the lower fixture to the test machine as shown in Figure 14. The specimens tested with these fixtures showed linear stress-strain curve up till the proportional limit stress indicating that the two swivels were effective in removing the bending from the specimens. Type- 3 fixtures were used for conducting rest of the ORNL tests and were distributed to the interlaboratory study participants for the round robin testing. 

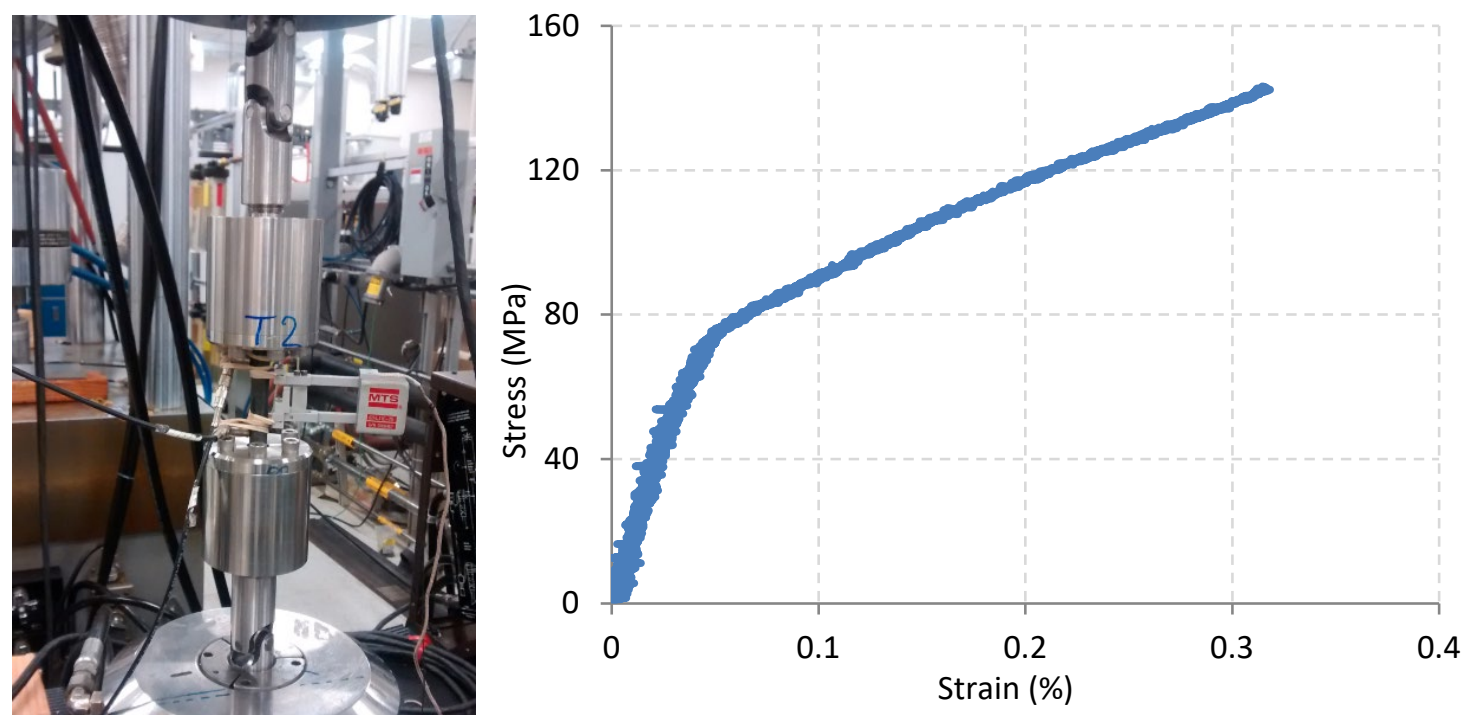

Figure 14: Swivel joints at top and bottom of the Type-3 fixture (left) removed bending from the specimen; a typical stress-strain curve for the specimens tested with this fixture.

Table 2 shows the mechanical properties of the $\mathrm{SiC} / \mathrm{SiC}$ composite tubes determined through the ORNL lead test. The data is based on dimensions measured through the caliper. Specimens 9, 10, 11, 12 and 13 were tested with Type-3 fixtures and specimens 1, 2, 3, 4 and 8 were tested with Type-2 fixtures. As mentioned earlier, some specimens tested with Type-2 fixtures showed non-linearity in the stress-strain curve. The Young's modulus for these specimens was determined using a portion of the initial stress-strain curve (within the elastic regime) which was closest to being linear. It should be noted that the results from the specimens which were tested with Type- 2 fixtures will not contribute to the determination of precision and bias of the test standard.

The scatter plots for Young's modulus, ultimate tensile strength (UTS) and proportional limit stress (PLS) are shown in figures 15 - 19. Figure 15 shows that Young's modulus was measured to be within 140 $-160 \mathrm{GPa}$ range for most of the specimens. The mean value, standard deviation and coefficient of variation were calculated to be $158.66 \mathrm{GPa}, 19.62 \mathrm{GPa}$ and $12.36 \%$ respectively. UTS values, shown in Figure 16 , ranged between $140-200 \mathrm{MPa}$. The mean value, standard deviation and coefficient of variation of UTS were calculated to be $171.52 \mathrm{MPa}, 19.62 \mathrm{MPa}$ and $11.44 \%$ respectively. The PLS, shown in Figure 17, was relatively more consistent in comparison to UTS, with a coefficient of variation of $7.59 \%$. For most specimens the PLS was measured to be within $65-75 \mathrm{MPa}$ range. The mean and standard deviation for PLS was found to be $72.45 \mathrm{MPa}$ and $5.50 \mathrm{MPa}$ respectively. Strain at failure is shown in Figure 18. The average failure strain for the specimens was found to be $0.46 \%$ indicating a very small deformation before failure. Strain values corresponding to PLS are shown in Figure 19. The coefficient of variation for the strain at PLS was $7.22 \%$, relatively smaller than the coefficient of variation for the strain at failure which was $19.55 \%$. A small coefficient of variation for PLS and strain at PLS $(\approx 7 \%)$ indicate the predictability of damage initiation in the material under mechanical loads.

Fractography will be performed on the tested specimen to get insights about the failure mechanisms of $\mathrm{SiC} / \mathrm{SiC}$ composite material. Figure 20 shows a SEM image of the cross section of a fractured specimen. The image shows matrix cracking and fiber pull-out occurred during the fracture of the specimen, which is typical for the $\mathrm{SiC} / \mathrm{SiC}$ composites. 
Table 2: Mechanical properties of $\mathrm{SiC} / \mathrm{SiC}$ tubes determined through the ORNL lead test*.

\begin{tabular}{|c|c|c|c|c|c|}
\hline Specimen ID \# & $\begin{array}{c}\text { Young's } \\
\text { modulus } \\
\text { (GPa) }\end{array}$ & UTS (MPa) & PLS (MPa) & $\begin{array}{c}\text { Strain at } \\
\text { failure (\%) }\end{array}$ & $\begin{array}{c}\text { Strain at } \\
\text { PLS (\%) }\end{array}$ \\
\hline $\mathbf{1}$ & 137.3 & 187.5 & 70.9 & 0.55 & 0.062 \\
\hline $\mathbf{2}$ & 168.0 & 199.0 & 65.1 & 0.59 & 0.049 \\
\hline $\mathbf{3}$ & 147.4 & 142.0 & 70.4 & 0.33 & 0.058 \\
\hline $\mathbf{4}$ & 150.1 & 159.6 & 70.7 & 0.40 & 0.057 \\
\hline $\mathbf{8}$ & 163.1 & 171.0 & 73.7 & 0.43 & 0.055 \\
\hline $\mathbf{9}$ & 153.6 & 179.7 & 68.4 & 0.52 & 0.054 \\
\hline $\mathbf{1 0}$ & 140.6 & 169.5 & 70.7 & 0.48 & 0.060 \\
\hline $\mathbf{1 1}$ & 201.0 & 195.1 & 85.6 & 0.52 & 0.053 \\
\hline $\mathbf{1 2}$ & 178.9 & 143.2 & 76.2 & 0.32 & 0.053 \\
\hline $\mathbf{1 3}$ & 146.6 & 168.8 & 72.8 & 0.47 & 0.060 \\
\hline Average & 158.66 & 171.52 & 72.45 & 0.46 & 0.056 \\
\hline $\begin{array}{c}\text { Standard } \\
\text { deviation }\end{array}$ & 19.62 & 19.62 & 5.50 & 0.09 & 0.004 \\
\hline $\begin{array}{c}\text { Coefficient of } \\
\text { variation (\%) }\end{array}$ & 12.36 & 11.44 & 7.59 & 19.55 & 7.22 \\
\hline Specis
\end{tabular}

* Specimens 1, 2, 3, 4 and 8 were tested with Type-2 fixtures while specimens 9 - 13 were tested with Type-3 fixtures. Statistics include both the data.

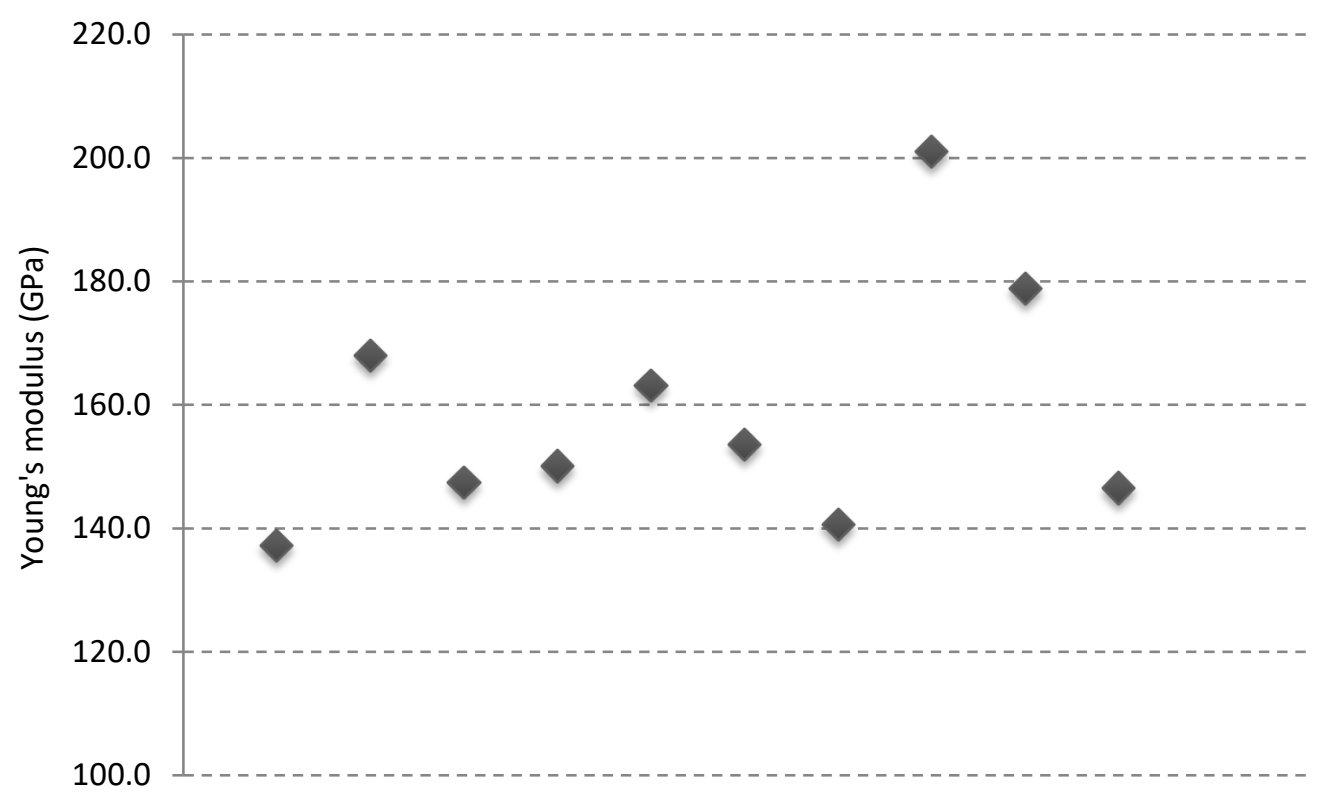

Figure 15: Young's modulus of $\mathrm{SiC} / \mathrm{SiC}$ composite determined through the ORNL lead test. 


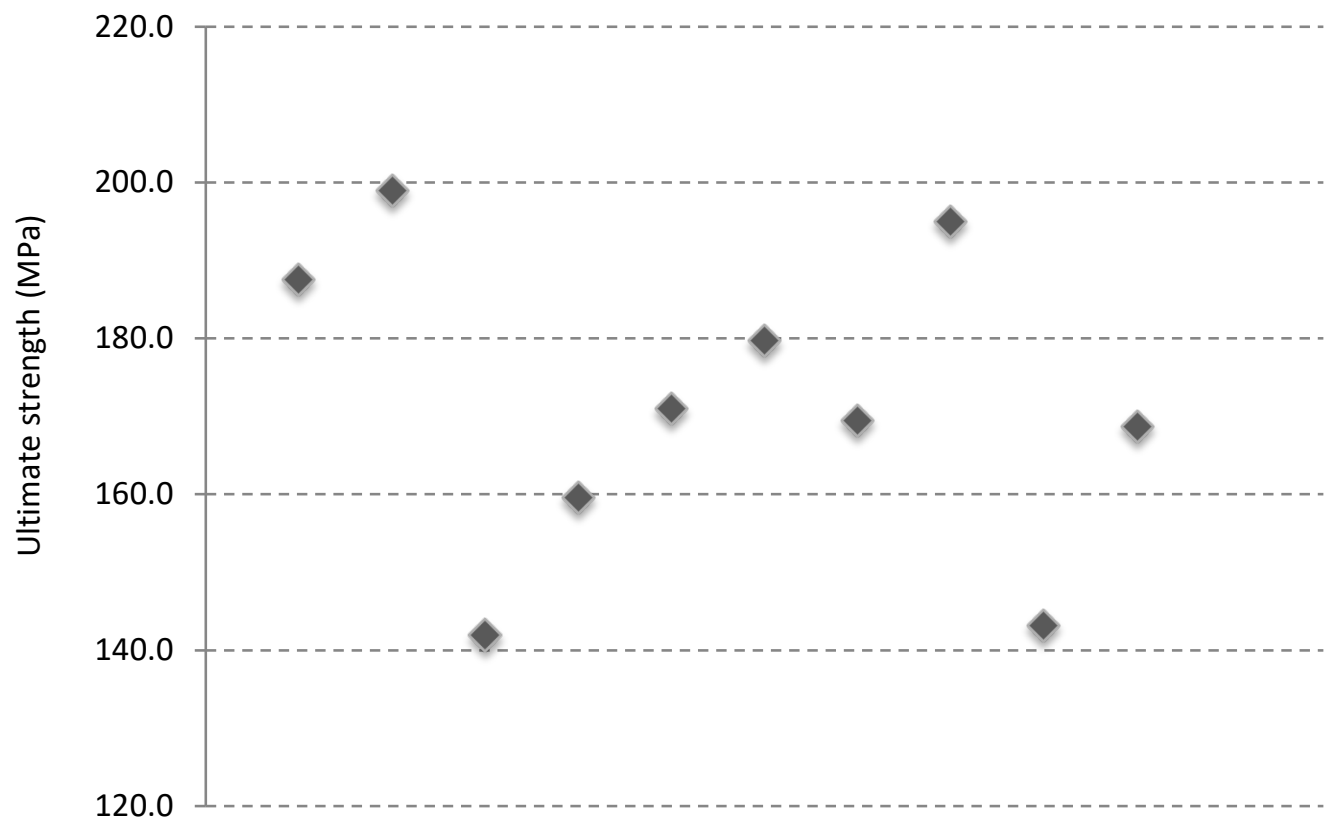

Figure 16: Ultimate tensile strength of $\mathrm{SiC} / \mathrm{SiC}$ composite determined through the ORNL lead test.

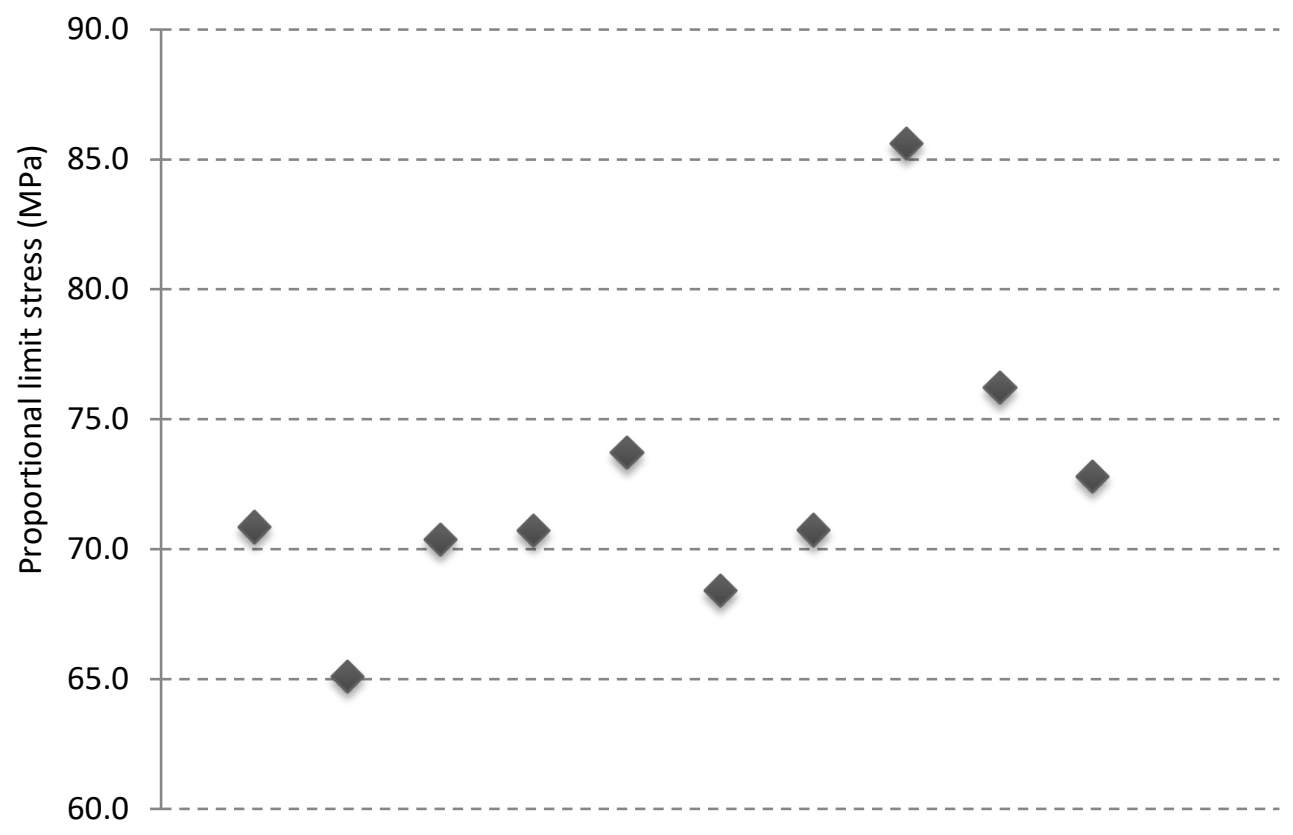

Figure 17: Proportional limit stress of $\mathrm{SiC} / \mathrm{SiC}$ composite determined through the ORNL lead test. 


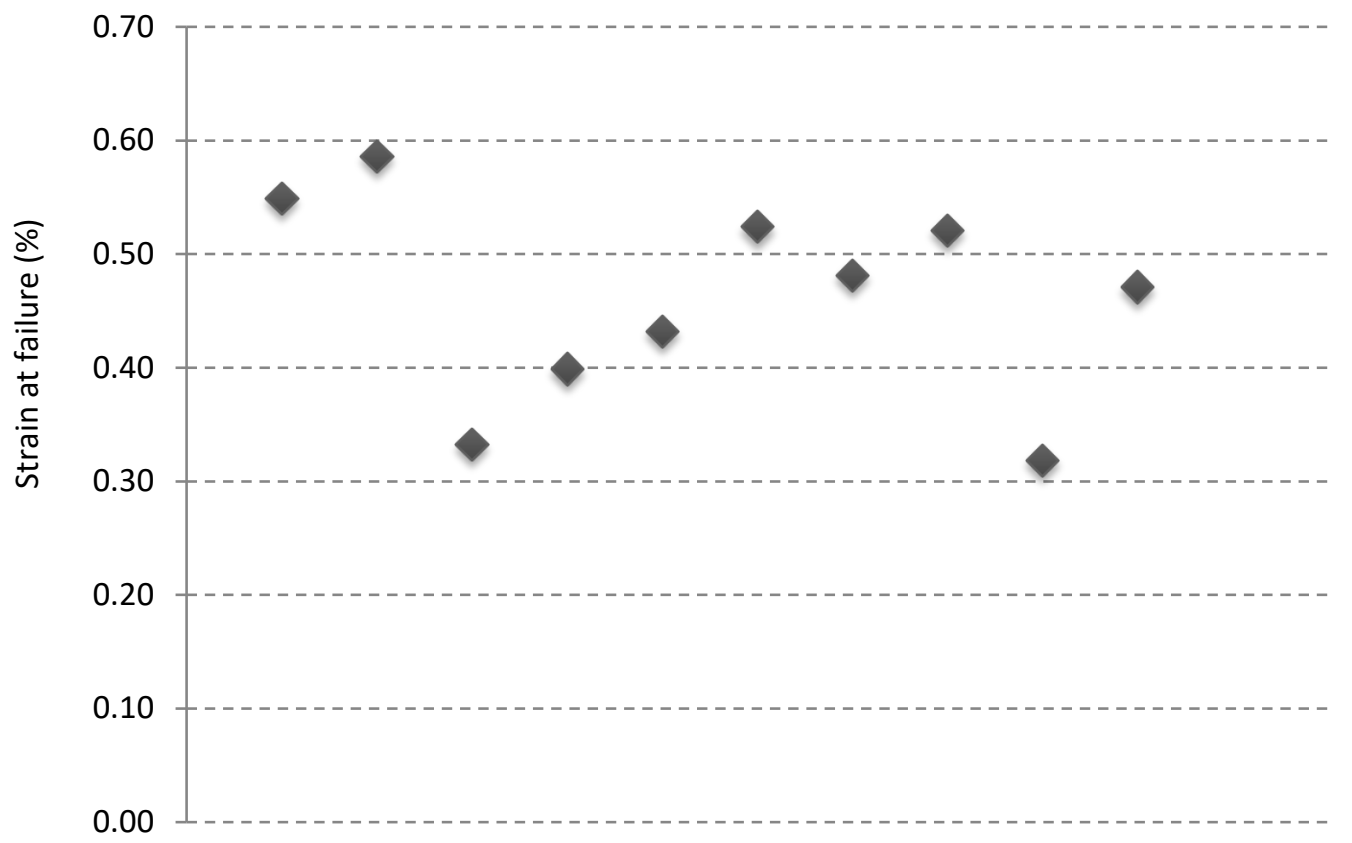

Figure 18: Strain at failure of $\mathrm{SiC} / \mathrm{SiC}$ composite determined through the ORNL lead test.

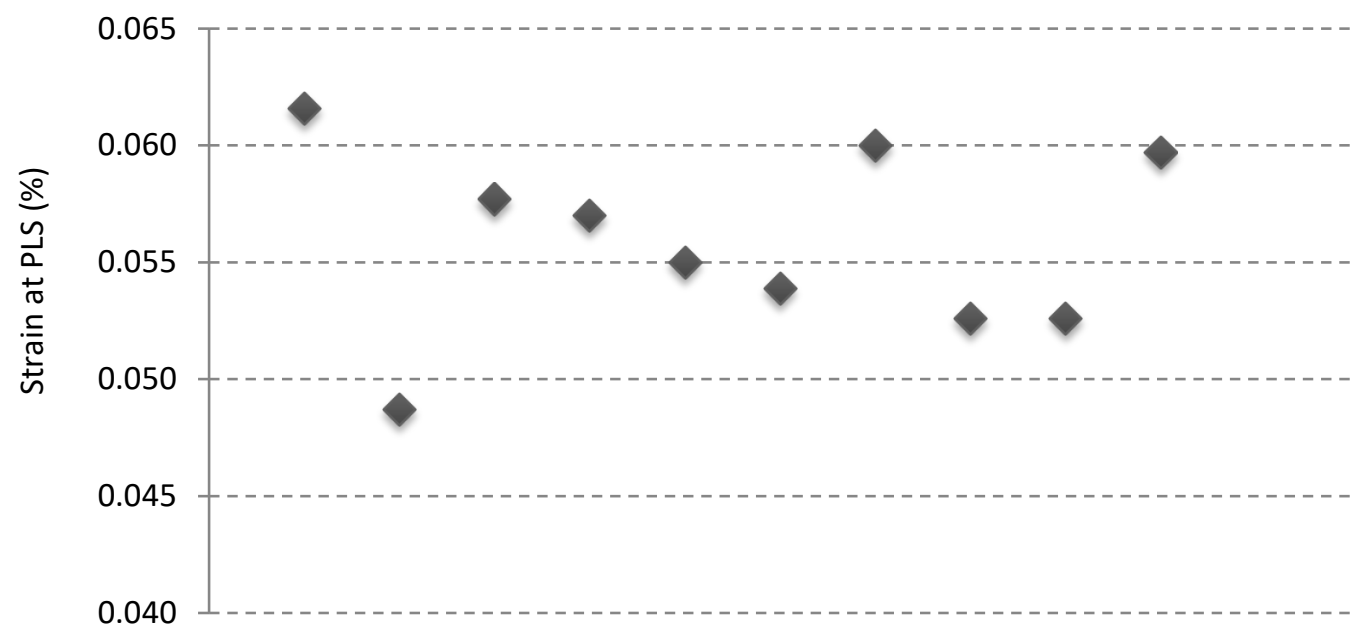

Figure 19: Strain at proportional limit stress (PLS) of $\mathrm{SiC} / \mathrm{SiC}$ composite determined through the ORNL lead test. 


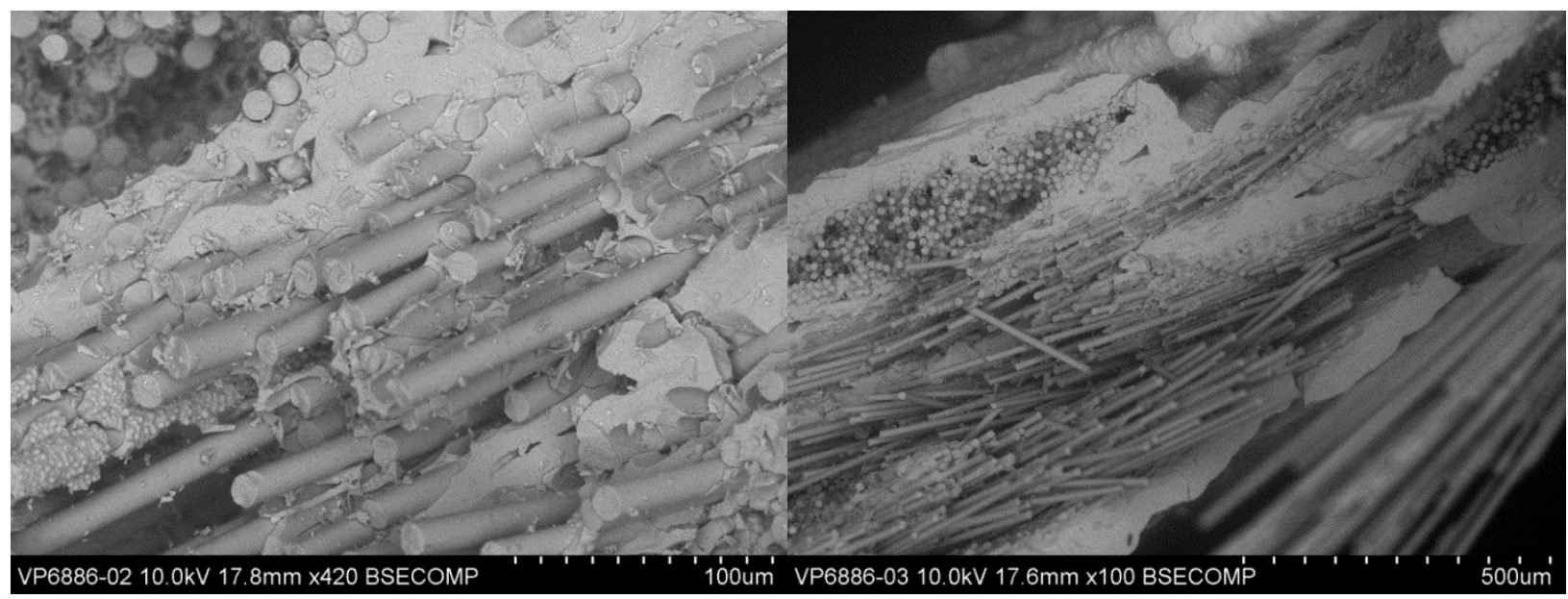

Figure 20: SEM image of the fractured surface of a $\mathrm{SiC} / \mathrm{SiC}$ tube specimen.

\section{SUMMARY}

$\mathrm{SiC} / \mathrm{SiC}$ is a leading candidate material for the accident tolerant fuel cladding systems in LWRs because of its unique set of properties. However, the material has to pass several feasibility studies and satisfy criteria of many rigorous tests before it can be deployed and commercialized for nuclear reactors. Therefore, a rich database of nuclear grade $\mathrm{SiC} / \mathrm{SiC}$ properties and standard test procedures, through which the material can be unbiasedly characterized, are much needed. The work present herein addresses these needs on the development path of $\mathrm{SiC}$ clad technology through an interlaboratory round robin testing of the $\mathrm{SiC} / \mathrm{SiC}$ composite tube specimens.

The tube specimens used in this study were specifically designed for the interlaboratory round robin testing. These tube specimens are made of nuclear grade $\mathrm{SiC} / \mathrm{SiC}$ composite material: with the constituents as CVI SiC matrix, Hi-Nicalon Type $\mathrm{S}$ fibers and pyrocarbon interphase, which are stable under the neutron irradiation. In addition to the material, the architecture and the associated properties were selected such that the specimens represent a typical accident tolerant fuel cladding. Based on the results from the ORNL lead tests, the design of the specimens was further modified to improve the success of the round robin testing.

The requirements of the ASTM standard test method for axial tensile test (ASTM C1773-13) of continuous-fiber reinforced ceramic composite tubes are rigorously implemented through the test protocol which was developed specifically for the round robin testing. Besides implementing the ASTM standard requirements, the test protocol provides specific details related to the testing of the tube specimens employed in this study. The findings from the ORNL lead test were added to the test protocol to make it more comprehensive and robust.

The ORNL lead test was conducted to determine and address the potential issues with the testing of the $\mathrm{SiC} / \mathrm{SiC}$ tube specimens. A series of axial tensile tests were conducted. The issues of bending in the specimen and grip section failure were identified and resolved through change in the design of the fixtures and steel plugs in the specimen. A test protocol was drafted which rigorously implements the requirements of the ASTM C1773-13 test standard for axial testing of CFCC tubes. The findings of the ORNL lead tests were incorporated in the test protocol to make the test method robust.

With the objective of expanding the limited database of $\mathrm{SiC} / \mathrm{SiC}$ composite material interlaboratory round robin study has been initiated. Under the study seven labs - Southern Research Institute, NASA Glenn Research Center, California State University, United Technology Research Center, General Atomics and General Electric will conduct axial tensile tests on ORNL-provided $\mathrm{SiC} / \mathrm{SiC}$ tube specimens. These tests will be conducted independently at each lab and according to the ASTM C1773-13 standard and the test protocol mentioned before. Table 3 shows the status of the round robin testing at the time of submission of this report. The fixtures, test specimens and other parts for testing were distributed to three laboratories. For two laboratories specific parts required for their test machines were being prepared for distribution; information on the specific requirements for test fixtures was being awaited for one laboratory. 
Table 3: Current list of committed participants to the interlaboratory round robin testing.

\begin{tabular}{|c|c|c|}
\hline Participating Institution & Contact Person & Status \\
\hline General Atomics & Christian Deck & Specimens \& test fixtures sent \\
\hline $\begin{array}{l}\text { California State University } \\
\text { Fresno }\end{array}$ & Michael Jenkins & $\begin{array}{l}\text { Waiting for information on the specific } \\
\text { requirements for test fixtures }\end{array}$ \\
\hline NASA Glenn Research Center & Jon Salem & Specimens \& test fixtures sent \\
\hline $\begin{array}{l}\text { United Technology Research } \\
\text { Center }\end{array}$ & Greg Ojard & $\begin{array}{l}\text { Test fixture parts specific for test machine } \\
\text { being prepared }\end{array}$ \\
\hline Southern Research Institute & Jacques Cuneo & $\begin{array}{l}\text { Test fixture parts specific for test machine } \\
\text { being prepared }\end{array}$ \\
\hline General Electric - Aviation & Bob Zhou & Specimens \& test fixtures sent \\
\hline
\end{tabular}

The interlaboratory round robin testing is expected to be completed during last quarter of year 2016 . The results of this study will be discussed during the annual meeting with ASTM C28 committee which is responsible for the development of ASTM C1773-13 standard. The results will be circulated among the scientific community through a journal publication. 


\section{REFERENCES}

[1] J. Carmack, F. Goldner, S. M. Bragg-Sitton, and L. L. Snead, "Overview of the US DOE accident tolerant fuel development program," in Proc. 2013 LWR Fuel Performance Meeting/TopFuel 2013, 2013, pp. 15-19.

[2] S. J. Zinkle, K. A. Terrani, J. C. Gehin, L. J. Ott, and L. L. Snead, "Accident tolerant fuels for LWRs: A perspective," Journal of Nuclear Materials, vol. 448, pp. 374-379, 2014.

[3] K. Yueh, D. Carpenter, and H. Feinroth, "Clad in clay," Nuclear Engineering International, vol. 55, pp. 14-16, 2010.

[4] K. Yueh and K. A. Terrani, "Silicon carbide composite for light water reactor fuel assembly applications," Journal of Nuclear Materials, vol. 448, pp. 380-388, 2014.

[5] K. E. Barrett, M. Teague, I. J. Van Rooyen, S. M. Bragg-Sitton, K. Ellis, C. Glass, et al., "Engineering challenges of LWR advanced fuel cladding technology in preparation for inreactor demonstrations," Oak Ridge National Laboratory (ORNL)2012.

[6] S. Fazluddin, K. Smit, and J. Slabber, "The use of advanced materials in VHTR's," in Second International Topical Meeting on High Temperature Reactor Technology, 2004.

[7] A. Kohyama, T. Hinoki, T. Mizuno, T. Kunugi, M. Sato, Y. Katoh, et al., "R\& D of Advanced material systems for reactor core component of gas cooled fast reactor," in Proceedings of the International Congress on Advances in Nuclear Power Plants, 2005, p. 19.

[8] A. Raffray, R. Jones, G. Aiello, M. Billone, L. Giancarli, H. Golfier, et al., "Design and material issues for high performance $\mathrm{SiC}$ f/SiC-based fusion power cores," Fusion Engineering and Design, vol. 55, pp. 55-95, 2001.

[9] N. B. Morley, Y. Katoh, S. Malang, B. A. Pint, A. Raffray, S. Sharafat, et al., "Recent research and development for the dual-coolant blanket concept in the US," Fusion Engineering and Design, vol. 83, pp. 920-927, 2008.

[10] Y. Katoh and K. A. Terrani, "Systematic Technology Evaluation Program for SiC/SiC Composite-based Accident-Tolerant LWR Fuel Cladding and Core Structures: Revision 2015," Oak Ridge National Laboratory (ORNL)2015.

[11] M. G. Jenkins, E. Lara-Curzio, S. T. Gonczy, and L. P. Zawada, "Multiple-Laboratory Round-Robin Study of the Flexural, Shear, and Tensile Behavior of a Two-Dimensionally Woven Nicalon ${ }^{\mathrm{TM}} /$ Sylramic ${ }^{\mathrm{TM}}$ Ceramic Matrix Composite," in Mechanical, Thermal and Environmental Testing and Performance of Ceramic Composites and Components, ed: ASTM International, 2000.

[12] Y. Katoh, K. Ozawa, C. Shih, T. Nozawa, R. J. Shinavski, A. Hasegawa, et al., "Continuous $\mathrm{SiC}$ fiber, CVI SiC matrix composites for nuclear applications: Properties and irradiation effects," Journal of Nuclear Materials, vol. 448, pp. 448-476, 2014.

[13] Y. Katoh, T. Nozawa, C. Shih, K. Ozawa, T. Koyanagi, W. Porter, et al., "High-dose neutron irradiation of Hi-Nicalon Type S silicon carbide composites. Part 2: Mechanical and physical properties," Journal of Nuclear Materials, vol. 462, pp. 450-457, 2015.

[14] T. Koyanagi, Y. Katoh, K. Ozawa, K. Shimoda, T. Hinoki, and L. L. Snead, "Neutronirradiation creep of silicon carbide materials beyond the initial transient," Journal of Nuclear Materials, vol. 478, pp. 97-111, 2016.

[15] H. M. Yun and J. A. DiCarlo, "Comparison of the tensile, creep, and rupture strength properties of stoichiometric $\mathrm{SiC}$ fibers," in Proceedings of the 23rd annual conference on composites, materials and structures, 1999, pp. 259-72.

[16] A. Urano, J.-i. Sakamoto, M. Takeda, Y. Imai, H. Araki, and T. Noda, "Microstructure and Mechanical Properties of SiC Fiber" Hi-Nicalon Type S" Reinforced SiC Composites," in 22nd Annual Conference on Composites, Advanced Ceramics, Materials, and StructuresA: Ceramic Engineering and Science Proceedings, Volume 19, 2009, p. 55. 
[17] M. Takeda, J. Sakamoto, A. Saeki, and H. Ichikawa, "Mechanical and structural analysis of silicon carbide fiber Hi-Hicalon type S," in Ceramic Engineering and Science Proceedings. vol. 17, No. 4, ed Westerville, OH: American Ceramic Society, 1996, pp. 3542.

[18] H. Ichikawa, "Polymer-Derived Ceramic Fibers," Annual Review of Materials Research, 2016.

[19] R. Naslain, "Design, preparation and properties of non-oxide CMCs for application in engines and nuclear reactors: an overview," Composites Science and Technology, vol. 64, pp. 155-170, 2004.

[20] T. Noda, H. Araki, H. Suzuki, and F. Abe, "Processing of carbon fiber/SiC composite for low activation," Materials Transactions, JIM, vol. 34, pp. 1122-1129, 1993.

[21] A. Kohyama, "Present status of NITE-SiC/SiC for advanced nuclear energy systems," in 31 st International Conference on Advanced Ceramics and Composites, Daytona Beach, 2007.

[22] T. Koyanagi, K. Ozawa, T. Hinoki, K. Shimoda, and Y. Katoh, "Effects of neutron irradiation on mechanical properties of silicon carbide composites fabricated by nanoinfiltration and transient eutectic-phase process," Journal of Nuclear Materials, vol. 448, pp. 478-486, 2014.

[23] D. P. Stinton, A. J. Caputo, and R. A. Lowden, "Synthesis of fiber-reinforced SiC composites by chemical vapor infiltration," American Ceramic Society Bulletin, vol. 65, pp. 347-350, 1986.

[24] A. Caputo and W. Lackey, "Fabrication of fiber reinforced ceramic composites by chemical vapor infiltration," 1984. 
This page intentionally left blank. 


\title{
APPENDICES
}

\author{
APPENDIX 1 - ILS PARTICIPATION AGREEMENT
}

\section{PARTICIPATION AGREEMENT}

ORNL and ASTM C28 INTERLABORATORY STUDY (ILS) ROUND ROBIN

ON AXIAL TUBE CMC TENSILE TESTING

June 2016 - July 2016

Our organization located in agrees to participate in the 2016

ASTM C28 ILS round robin on Axial Tube Tensile Testing of Ceramic Matrix Composites under the following terms and conditions:

1. We accept the set of SiC-SiC CMC tube test specimens and we will test them per the included project documents - ILS round robin ATT test plan and ASTM C1773. (See the task list on the following page.)

2. This testing will be done as a no-cost, in-kind participation in the ILS round robin project.

3. The CMC tube specimens will be used exclusively for the ILS round robin test. We will not do any other property testing or chemical/structural analysis on the CMC test specimens.

4. The CMC tube specimens are subject to U.S. federal export control requirements and will be protected and handled in accordance with applicable laws and regulations (ECCN: 1C007).

5. We will return all the fractured test specimens and the gripping system (fixtures, collets and swivel joints) after completion of testing to the project coordinator Gyanender Singh (Tel: (865) 574-5880, E-mail: singhgp@ornl.gov).

Please complete, sign, and return this agreement by e-mail or FAX before the start of testing to Gyanender Singh, ORNL, singhgp@ornl.gov Fax: (865) 241-3650. 


\section{APPENDIX 2 - GENERAL INSTRUCTIONS FOR CMC AXIAL TENSILE TUBE STRENGTH ILS}

STUDY

\section{Objective}

The objective of this ILS is to:

Determine the repeatability and reproducibility of the axial tensile tube (ATT) test method (ASTM C 1773 ) at ambient temperatures with one primary tube geometry for a SiC-SiC ceramic composite. The properties of interest are tensile ultimate strength and strain, proportional limit stress and strain, and elastic modulus in tension.

\section{Materials}

There is one (1) set of CMC ATT test specimens provided for the ILS study. Each set contains 8 test specimens.

The SiC-SiC ATT test specimens have been cut, finished, and measured at General Atomics and ORNL per the C1773 test standard. The specimens have been marked and logged with specimen identification numbers.

\begin{tabular}{|c|c|}
\hline \multicolumn{2}{|l|}{ Test Specimens } \\
\hline Composite & $\begin{array}{l}\text { SiC-SiC composite tubes - Two-dimensional }\left( \pm 55^{\circ}\right) \text { triaxial braiding with two braid } \\
\text { layers of Hi-Nicalon type } \mathrm{S} \mathrm{SiC} \mathrm{fibers} \mathrm{(monolayer} \mathrm{PyC} \mathrm{interface)} \mathrm{with} \mathrm{CVI} \mathrm{SiC} \\
\text { matrix. Produced by General Atomics Inc. }\end{array}$ \\
\hline $\begin{array}{l}\text { Specimen Geometry } \\
\text { and Size }\end{array}$ & $\begin{array}{l}\text { 6" }(150 \mathrm{~mm}) \text { long tube with } 8^{\circ} \text { tapered shoulders. Gage } \\
\text { OD: } 0.39 "(10 \mathrm{~mm}) \text {, Gage ID: } 0.34 "(8.6 \mathrm{~mm}), \\
\text { Nominal Wall Thickness: } 0.028^{\prime \prime}(0.7 \mathrm{~mm}) \text {, Gage length: } 2.76 ”(70 \mathrm{~mm})\end{array}$ \\
\hline $\begin{array}{l}\text { Nominal Composite } \\
\text { Mechanical Properties }\end{array}$ & $\begin{array}{l}\text { Tensile Strength: } \mathbf{1 5 0 - 2 0 0} \text { MPa, Strain at Failure: } \mathbf{0 . 5 \%}, \\
\text { Prop. Limit (PL) Stress (0.01\% offset): } \mathbf{6 0 - 9 0} \mathbf{~ M P a} \quad \text { PL Strain: } \sim \mathbf{0 . 0 6} \% \\
\text { Elastic Modulus: } \mathbf{1 5 0 - 2 0 0} \mathbf{~ G P a} \\
\text { Failure Mode: semi-brittle, pseudo-ductile }\end{array}$ \\
\hline Dimensional Tolerances & Per spec at General Atomics \\
\hline Specimen Preparation & Fabrication OD finish of all specimens at General Atomics \\
\hline Visual Inspection & At ORNL and at each test laboratory \\
\hline Measurement & $\begin{array}{l}\text { OD and ID Dimensions (at ORNL and each laboratory) } \\
\text { Ultrasound for wall thickness at ORNL and calipers pre- and post-test }\end{array}$ \\
\hline Conditioning & None \\
\hline
\end{tabular}




\begin{tabular}{|c|c|}
\hline nt anc & rs \\
\hline $\begin{array}{l}\text { Test Temperature/ } \\
\text { Environment }\end{array}$ & $\begin{array}{l}\text { Ambient temperature, no environmental chamber nor furnace required. } \\
\text { Humidity Measurement }\end{array}$ \\
\hline Test Machine & $\begin{array}{l}\text { Tensile loading with tensile load cell } \\
\text { (5 kip - } 22 \mathrm{kN} \text { capacity with } 1 \% \text { accuracy) }\end{array}$ \\
\hline Fixtures & Split copper collets, grip fixture and swivel joints (supplied by ORNL) \\
\hline X-Head Rate & $\begin{array}{l}0.0015-0.003 \mathrm{inch} / \mathrm{s} ; \text { typically } 30-60 \mathrm{~seconds} \text { failure time (suggested } \\
\text { rate: } 0.0005 \mathrm{inch} / \mathrm{s} \text { for load }<200 \mathrm{lbf} \text { and } 0.0025 \mathrm{inch} / \mathrm{s} \text { for higher load) }\end{array}$ \\
\hline $\begin{array}{l}\text { Extension and Strain } \\
\text { Measurement }\end{array}$ & $\begin{array}{l}\text { Strain measurement is required, either by clip-on extensometer/s } \\
\text { (1" gage recommended) or by two or more strain gages. }\end{array}$ \\
\hline $\begin{array}{l}\text { Alignment and Bending } \\
\text { Stress Check }\end{array}$ & $\begin{array}{l}\text { Strain gaged alignment specimen provided by ORNL. } \\
\text { Testing laboratories will check alignment in their systems. }\end{array}$ \\
\hline $\begin{array}{l}\text { Specimen Dimensions } \\
\text { Measurement }\end{array}$ & $\begin{array}{l}\text { Precision Calipers/Micrometers pre and post test. } \\
\text { Ultrasound for wall thickness at ORNL }\end{array}$ \\
\hline $\begin{array}{l}\text { Measured and recorded } \\
\text { test data }\end{array}$ & Applied force and extension/strain as a function of time/X-head movement. \\
\hline Data Collection & $\begin{array}{l}\text { Digital (force and extension/strain vs. time, and max force ) } \\
\text { Suggested collection rate }-40 \text { points per second }\end{array}$ \\
\hline Calculated data & $\begin{array}{l}\text { Ultimate tensile strength, Ultimate tensile strain, Elastic modulus } \\
\text { Proportional limit (PL) stress and PL strain }(0.01 \% \text { offset })\end{array}$ \\
\hline Fracture Analysis & Will be done at ORNL \\
\hline
\end{tabular}

\section{The ILS test package contains the following items}

1. Introduction letter

2. Participation agreement (Appendix 1) to use the specimens only for the axial tensile strength testing and return all the test specimens, alignment specimen and the gripping system (fixtures, collets and swivel joints) after the test.

3. Test instructions (Appendix 2) and a procedure checklist (Appendix 3).

4. A copy of the ASTM C1773 ATT test method, printed (Appendix 4).

5. One test specimen set with 8 ATT test specimens in each set, ready for testing.

6. An alignment specimen with applied resistance strain gages.

7. The two collet grip fixtures (top and bottom) for the ATT tests.

8. Copper split collets for the test specimens ( 8 sets of 4 half-split collets ( 2 top \& 2 bottom)).

9. Two swivel joints.

10. The following items will be sent through email:

a) Data report in a MS- EXCEL ${ }^{\text {TM }}$ spreadsheet format (ATTDataSheet.XLS),

b) Dimensions of the test specimens in a MS- EXCEL ${ }^{\mathrm{TM}}$ spreadsheet and

c) Pdf version of the ASTM C1773 ATT test method.

11. A printed copy of the MS- EXCEL ${ }^{\mathrm{TM}}$ data spread sheet format for your review. (Appendix 5)

\section{Specific Tasks for the ILS ATT Test Laboratories}

The ATT testing of the SiC-SiC tube test specimens will be done by six laboratories according to the ASTM C1773 test standard with their in-house testing test equipment, using the supplied grip fixtures, copper split collets and swivel joints. 
The success and value of the ILS effort depends on three factors:

1. All of the CMC ceramic test specimens in each test set are uniform in physical and mechanical properties.

2. All of the participating laboratories prepare their equipment, measure the specimens, and perform the ATT tests according to the ASTM C1773 test standard (Appendix 4) and the procedure checklist (Appendix 3).

3. The participating laboratories complete the testing in a timely manner (no later than one month after receiving the specimens and fixtures unless agreed otherwise) and promptly return the Excel spread sheet file with all the formatted test data and fractured specimens to the test coordinator.

The specific tasks for the tensile testing laboratories are listed below. These tasks request information beyond the minimum requirements of ASTM C1773 to evaluate the robustness of the standard test method. 


\section{APPENDIX 3 - AXIAL TUBE TENSILE TESTING CHECKLIST}

\section{Return this completed check list with your test data for each test specimen set.}

The tasks in the checklist request information beyond the requirements of the draft test standard to evaluate the robustness of the standard test method.

Technical Contact for ATT Testing:

Gyanender Singh

Oak Ridge National Laboratory

Tel: (865) 574-5880 E-mail: singhgp@ornl.gov

\begin{tabular}{|l|}
\hline Laboratory Name \\
\hline Contact \& Phone \\
\hline E-Mail Address \\
\hline Test Date \\
\hline ORNL SiC-SiC 05-16 Spec ID \# \\
\hline
\end{tabular}

The schedule for completing the testing and returning the test pieces to the ILS coordinator Gyanender Singh: no later than one month after receiving the specimens and fixtures unless agreed otherwise.

There are six sections to

this checklist:

1 Initial Test Specimen Check and Planning

2 Test Specimen Preparation

3 Equipment Check and Set-up

4 Tensile Testing (Ambient Temperature)

5 Calculation, Data Recording \& Review

6 Return Data and Test specimens

\section{INITIAL TEST SPECIMEN CHECK \& TEST PLANNING}

Step $\frac{\text { Check ACTION }}{\text { Box }}$

\section{Reference to} ASTM C1773

$1 \quad \square \quad$ Count the number of test specimens against the shipping documents- NA eight (8) test specimens in the test set). Check each specimen for breaks, surface cracks, or warping. (Call the test coordinator, if the test specimen sets are incomplete or test specimens are broken, cracked, or damaged)

$2 \quad$ Check the legibility of the specimen ID numbers on the test specimen packages. 
vent handling damage and minimize temperature and humidity

Sec. 9.10 extremes.

$4 \quad \square \quad$ Review the ASTM C1773 standard and these ILS instructions.

Test Instructions

5

Review the Excel data report spread sheet for format and content.

Test Instructions

$6 \quad \square$ Determine how the grip fixtures will fit into your test system load train,

Test Instructions maintaining alignment and force application.

\section{TEST SPECIMEN PREPARATION and MEASUREMENT}

\section{Step $\frac{\text { Check }}{\text { Box }}$ ACTION}

1. $\square$ Open the packaging of the test specimens and check the test specimens and copper split collets for damage.

2. $\square$ Check the accuracy and calibration of your flat anvil micrometer and your knife edge calipers.

Use the micrometer for pre-test OD measurements.

Use the calipers for post-test $O D$ and wall thickness measurements.

3. $\square \quad$ Note and record the ID number for each test specimen.

4. $\square$ Measure and record outer diameter $\left(d_{0}\right)$ of each test specimen at 9 points ( 3 points around the circumference at three locations (center, center $-30 \mathrm{~mm}$, center $+30 \mathrm{~mm}$ ) along the gage section length, with total 9 measurements) Measure to an accuracy of 0.01 $\mathrm{mm}$.

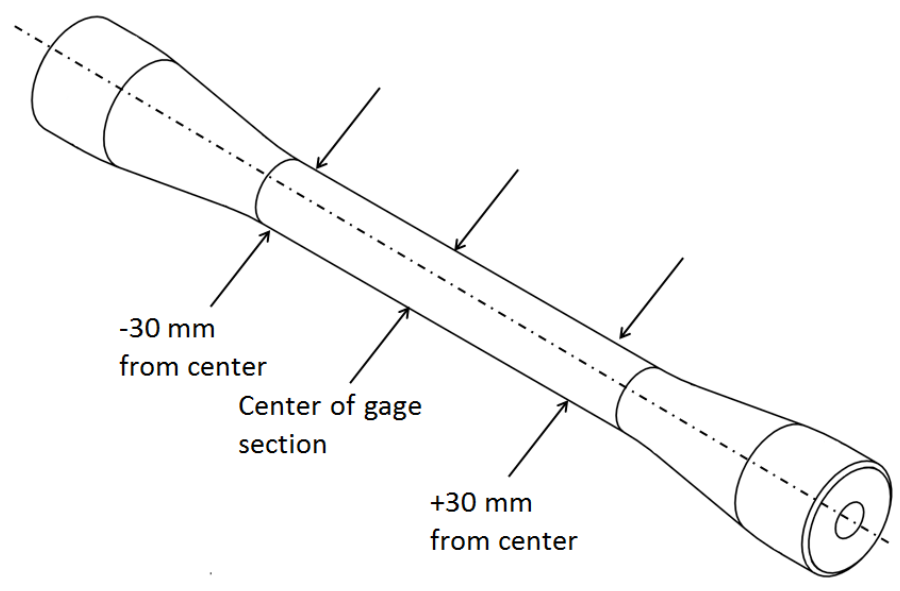

Measure and record the overall length of the test specimen and the length of the gage section (2 measurements). Measure to an accuracy of $1 \mathrm{~mm}$.

\section{Reference to} ASTM C1773

NA

$\operatorname{Sec} 10.4 .1$

Sec. 7.3.7

Sec. 7.3.4

$\operatorname{Sec} 10.3$ 
Sec 10.3.2

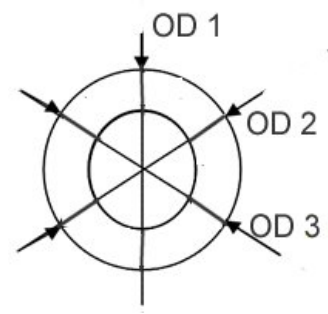


5. $\square$ If resistance strain gages (12 $\mathrm{mm}$ length suggested) are used, install the strain gages per the test standard and record the locations.

$\operatorname{Sec} 7.3 .2$

(Minimum of 2 strain gages -- at the center of the gage section, $180^{\circ}$ apart.

Preferred - 4 strain gages -- 2 gages $20 \mathrm{~mm}$ down from gage center at $0^{\circ}$ and $180^{\circ}$ and 2 gages $20 \mathrm{~mm}$ up from gage center at $90^{\circ}$ and $270^{\circ}$ )

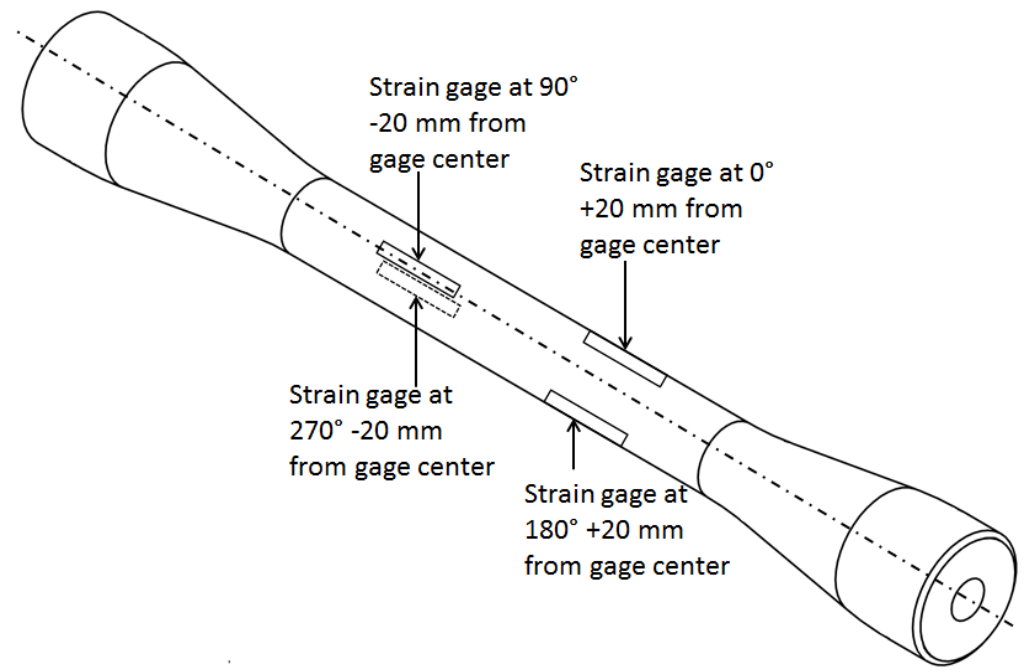

\section{EQUIPMENT CHECK and SET-UP}

\section{Step Check ACTION}

1. $\quad$ Has the testing machine load cell been calibrated to ASTM

standard in the last 12 months? If not, calibrate.

2. $\square$ Can the tensile load cell handle at least 10,000 Newton (the maximum expected breaking load)? A 20,000 Newton (5000 lbf) load cell) is recommended.

Does the load cell have an accuracy and resolution of at least 20 Newton or better?

3. $\square$ Are the data recording/acquisition devices calibrated and checked

5. out? Data acquisition rate should be fast enough to capture the resolution of $20 \mathrm{~N}$, i.e. $40 \mathrm{~Hz}$

4. $\square$ Position, center, and align the top and bottom collet grip fixtures. 
e alignment specimen, check that the load train is properly aligned and that the bending is less than $5 \%$.

6. $\square$ Set up the strain measurement system for either extensometer or

Sec. 7.3.3 and 10.1

Sec. 7.2 and

11.2.2.1

Sec. 10.5

Sec. 10.7 
7. Set the test control mode for "displacement". There may be slack in the load train during the initial part of loading (<150 lbf / $667 \mathrm{~N}$ ); a and 11.1 low cross-head speed is recommended during the slack (suggested speed: 0.0005 inch/s)]. After reaching a load level of $150 \mathrm{lbf}$, a higher cross-head speed of $0.0015-0.003$ inch/s is recommended (suggested speed: 0.0025 inch/s). After slack removal failure should occur within 30 to 60 seconds.

\section{ATT TESTING}

\section{Step Check ACTION

1. Check the specimen ID numbers

2. Measure and record the ambient temperature and humidity at the beginning of the test session.

3. Position and center the test specimen with the copper split collets in the

$\operatorname{Sec} 10.6$ split collet grip fixture.

Mark the test specimen for orientation.

4. Strain Measurement:

Mount, connect, and check the extensometer gage on the test specimen. OR Connect and balance the strain gages, if they are used.

5. Activate and adjust the testing machine for initial cross-head position, zero load, displacement test mode, and cross head speed.

6. Activate and check the data acquisition system.

Sec 10.10 and 10.11 .2

7. Preload the specimen with approximately 25-40 Newton to maintain

$\operatorname{Sec} 10.11 .2$ specimen alignment.

8. Start the test by activating the cross-head movement and the data recorder.

$\operatorname{Sec} 10.11 .3$

Record and store the force-strain data for each test.

9. Apply force until the test specimen fractures or there is a drop of $50 \%$ from the maximum observed force

$\operatorname{Sec} 10.11 .4$ 
10. Measure and record the peak/failure force (Newton) and the failure strain (\%) Sec 10.11.4 against the specimen ID \#.

Sec.10.11.5

Stop the data acquisition

Remove the broken specimen segments from the grip fixture.

Return the cross-head to the zero position.

11. Note and record if the test is invalid or censored because of failure in the grip

Sec.10.12.1 sections or outside the gage section.

12. $\square$ With the calipers measure and record

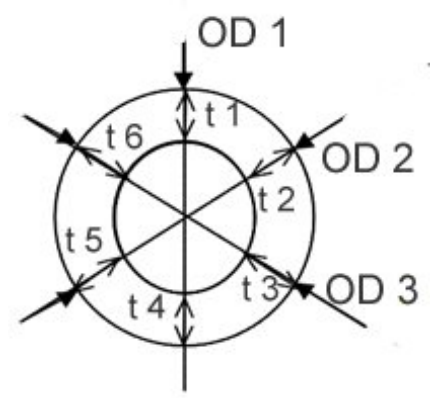

Sec. 10.13 .1 the OD and wall thickness on each specimen at three spans around the circumference close to the fracture point ( 3 OD measurements and 6 wall thickness measurements).

13. Note and record where the fracture location is with respect to the center of the gage section (e.g.,10 mm up or down from the gage center) 


\section{Calculation, Data Recording and Data Review}

$\begin{array}{ll}\text { Step Check } & \text { Action } \\ \text { Box } & \begin{array}{l}\text { Using the fracture force }(\mathrm{N}) \text { and the original cross section area }\left(\mathrm{mm}^{2}\right) \\ \text { (based on average OD and wall thickness measurements), calculate } \\ \text { the axial fracture strength (MPa) (This is done automatically in the } \\ \text { EXCEL data sheet). }\end{array}\end{array}$

$\square \quad$ Using the elastic section of the stress-strain curve, calculate and record the tensile elastic modulus (GPa).

U Using the $0.01 \%$ offset method against the elastic section of the stress-strain curve, calculate and record the proportional limit stress (MPa) $(0.01 \%$ offset) and PL strain (\%).

$\square \quad$ Record the test data (experimental parameters, specimen data, and test results) in the Excel spread sheet. (File: ATTDataSheet.xls).

$\square \quad$ Review the report test data (test parameters, test specimen data, and test results- Appendix 5) and ensure that data are complete and accurate with no typographical errors

- Transfer the force-extension/strain data for each test to the Excel spread sheets, identified by test specimen ID.

Save the completed Excel data spread sheet (File: ATTDataSheet.xls).
Reference to

ASTM C1773

Sec. 11.4

Sec. 11.5

Sec. 11.7

Sec. 12

Sec. 12

Test Instr.

Test Instr.

\section{RETURN DATA AND TEST SPECIMENS}

Send the completed Excel data spreadsheet file along with the force- Test Instr. displacement data to Gyanender Singh by e-mail. (singhgp@ornl.gov)

Prepare the test specimen package for shipping with the following:

The package with the broken test specimens.

Alignment specimen

A hardcopy of the completed checklist for the test specimen set.

Prepare the gripping system package for shipping with the following:

Gripping system (fixtures, collets and swivel joints)

Securely send the packages to:

Gyanender Singh

Oak Ridge National Laboratory || One Bethel Valley Road MS-6136

A-155, Building 4500S || Oak Ridge, TN 37831-6136

(865) 574-5880

The schedule for completing the testing and returning the test pieces to the ILS coordinator Gyanender Singh: within one month of receiving the test specimens and fixtures unless agreed otherwise. 


\title{
APPENDIX 4 - INVITATION LETTER FOR THE INTERLABORATORY PARTICIPANTS
}

\author{
ILS -- Axial Tensile Strength of Ceramic Matrix Composite Tubes
}

\section{ASTM C-28 AdVANCED CERAMICS COMMITTEE}

Date

Name of laboratory contact

Organization name

Street Address

City, State PIN

Dear Potential participant name,

We are ready to begin our interlaboratory study (ILS) on the uniaxial tensile strength of ceramic matrix composite tubes, using the new ASTM C1773 Standard Test Method (Monotonic Axial Tensile Behavior of Continuous Fiber-Reinforced Advanced Ceramic Tubular Test Specimens at Ambient Temperature). The objective of this first ILS is to:

Determine the repeatability and reproducibility of the axial tensile tube (ATT) test method (ASTM C 1773) at ambient temperatures for a SiC-SiC ceramic composite with one primary tube geometry. The properties of interest are ultimate tensile strength and strain, proportional limit $(0.01 \%$ offset $)$ stress and strain, and elastic modulus in tension.

We have laid out a detailed experimental plan for the ILS, using a $\mathrm{SiC}-\mathrm{SiC}$ composite tube with a defined geometry (6" long tube with $8^{\circ}$ tapered shoulders, gage OD $=0.39$ ", gage ID $=0.34$ ", nominal gage length $\left.=2.76^{\prime \prime}\right)$. The CMC tube test specimens will be tested at ambient temperature. Each test set will have 8 test specimens for each participating laboratory. (The full test plan and instructions are laid out in Appendix 2.)

Test specimen sets are being sent to you and 4 other laboratories for testing. This test package contains the following items:

1. Introduction letter

2. Participation agreement (Appendix 1) to use the specimens only for the axial tensile strength testing and return all the test specimens after the test.

3. Test instructions (Appendix 2) and a procedure checklist (Appendix 3).

4. A copy of the ASTM C1773 ATT test method, printed (Appendix 4).

5. One test specimen set with 8 ATT test specimens in each set, ready for testing.

6. An alignment specimen with applied resistance strain gages.

7. The two collet grip fixtures (top and bottom) for the ATT tests.

8. Copper split collets for the test specimens. ( 8 sets of 4 half-split collets ( 2 top \& 2 bottom))

9. Two swivel joints.

10. The following items will be sent through email:

a) Data report in a MS- EXCEL ${ }^{\text {TM }}$ spreadsheet format (ATTDataSheet.XLS),

b) Dimensions of the test specimens in a MS- EXCEL ${ }^{\mathrm{TM}}$ spreadsheet and

c) Pdf version of the ASTM C1773 ATT test method. 
11. A printed copy of the MS- EXCEL ${ }^{\mathrm{TM}}$ data spread sheet format for your review. (Appendix 5)

With these test specimens, grip fixtures and swivel joints, collets, alignment specimen, and instructions, you have the materials and information needed to complete your portion of the ILS. The detailed ILS testing tasks are listed in Appendix 1, page 3 and in the ILS check list (Appendix 3)

The success and value of the ILS effort depends on three factors:

1. All of the CMC tube test specimens in each test set are uniform in physical and mechanical properties.

2. All of the participating laboratories prepare their equipment, measure the specimens, and perform the ATT tests according to the ASTM C1773 test standard (Appendix 4) and the test procedure checklist (Appendix 3).

3. The participating laboratories complete the testing in a timely manner and promptly return all the formatted test data, fractured test specimens and the gripping system (fixtures, collets and swivel joints) to the test coordinator.

For scheduling purposes, we would like the testing and data reporting to be completed within one month after you receive the test specimens and fixtures unless agreed otherwise.

If you have technical (samples or testing procedures) or administrative (data and reporting requirements, shipping/packaging) questions about this package and the test specimens, please contact:

Gyanender Singh/Yutai Katoh

Oak Ridge National Laboratory

Tel: (865) 574-5880

E-mail: singhgp@ornl.gov
Stephen T. Gonczy

Gateway Materials Technology Inc.

Tel: (847) 870-1621

E-Mail: gatewaymt@aol.com

Your participation in the ILS is much appreciated. We look forward to your contribution of time and effort to this technical project which supports aerospace and nuclear ceramic composites technology and the development of ASTM advanced ceramics standards.

Gyanender Singh/Yutai Katoh

Materials Science and Technology Division

Oak Ridge National Laboratory

Oak Ridge, TN 37831
Stephen Gonczy

Gateway Materials Technology

$221 \mathrm{~S}$. Emerson

Mount Prospect, IL 60056 


\section{TASK LIST FOR THE AXIAL TUBE TENSILE (ATT) TEST ILS STUDY}

\section{PACKAGE RECEIPT AND SPECIMEN CHECK}

1. Check the test package for completeness -- the ILS instructions, the procedure checklist (Appendix 3), the ASTM C1773 standard (Appendix 4), and the included the 8 test specimens, grip fixtures, 8 collets sets, swivel joints, the alignment specimen, the test data report EXCEL file, and the specimen dimension Excel File.

2. Review the test plan and procedures described in this letter and appendix. Review, sign, and return (e-mail or fax) the participation agreement (Appendix 2) to Gyanender Singh (singhgp@ornl.gov,_Fax (865) 241-3650).

3. Check the count and condition of the SiC-SiC specimens in the test set and store them in their original packaging in a desiccator until testing.

4. Check the alignment specimen, the two grip fixtures and swivel joints, and the 8 sets of copper split collets for count and condition. Check how the grip fixtures will be fitted into your test system, accounting for proper alignment.

\section{Specimen Tensile Testing}

5. Review the ILS instructions, the procedures checklist (Appendix 3), and the ASTM C1773 test standard (Appendix 4).

6. Set up and check the testing equipment for specimen insertion and alignment, force measurement, displacement control, and strain measurement, per the attached checklist (Appendix 3) and the ASTM C1773 test standard (Appendix 4)

7. Complete 8 ATT tests per the attached checklist (Appendix 3) and the ASTM C1773 standard (Appendix 4). Use and complete the checklist to ensure proper testing.

8. Measure and record the OD and wall thickness of each specimen at three points close to the fracture site.

9. Record (in the MS-EXCEL file) and review the specimen data, experimental data, test data, and forceextension/strain data for completeness and accuracy. Send the completed data EXCEL spread sheet file by e-mail to Gyanender Singh (singhgp@ornl.gov)

10. Collect, pack and send the fractured test specimens and completed checklists to Gyanender Singh at the address given below.

Gyanender Singh

Oak Ridge National Laboratory

One Bethel Valley Road MS-6136

A-155, Building 4500S

Oak Ridge, TN 37831-6136

(865) 574-5880 


\section{APPENDIX 6 - AXIAL TENSILE TEST STRESS-STRAIN CURVES FOR THE SIC/SIC SPECIMENS}

Specimens 9, 10, 11, 12 and 13 were tested with Type-3 fixtures and specimens 1, 2, 3, 4 and 8 were tested with Type-2 fixtures.

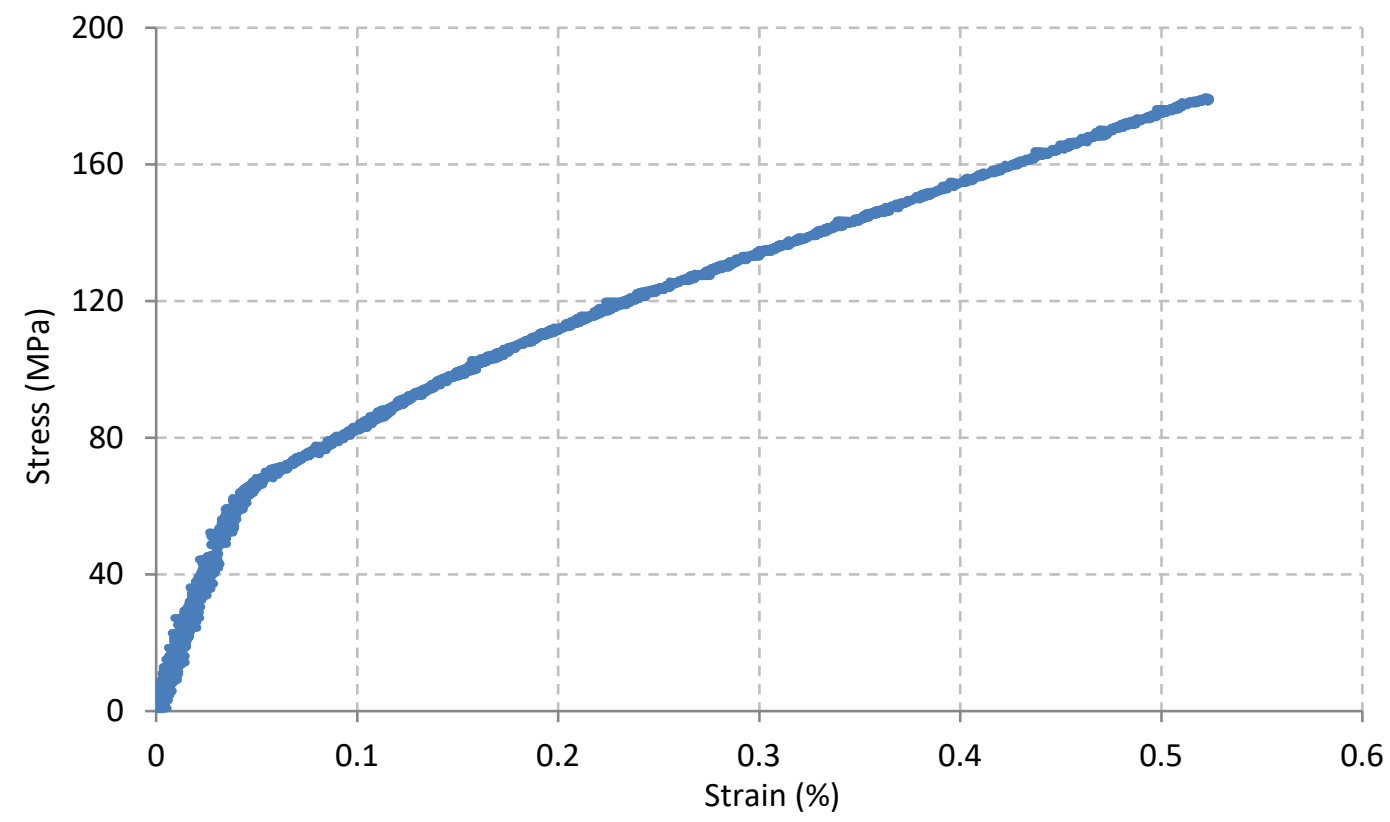

Figure 21: Stress-strain curve for specimen-9.

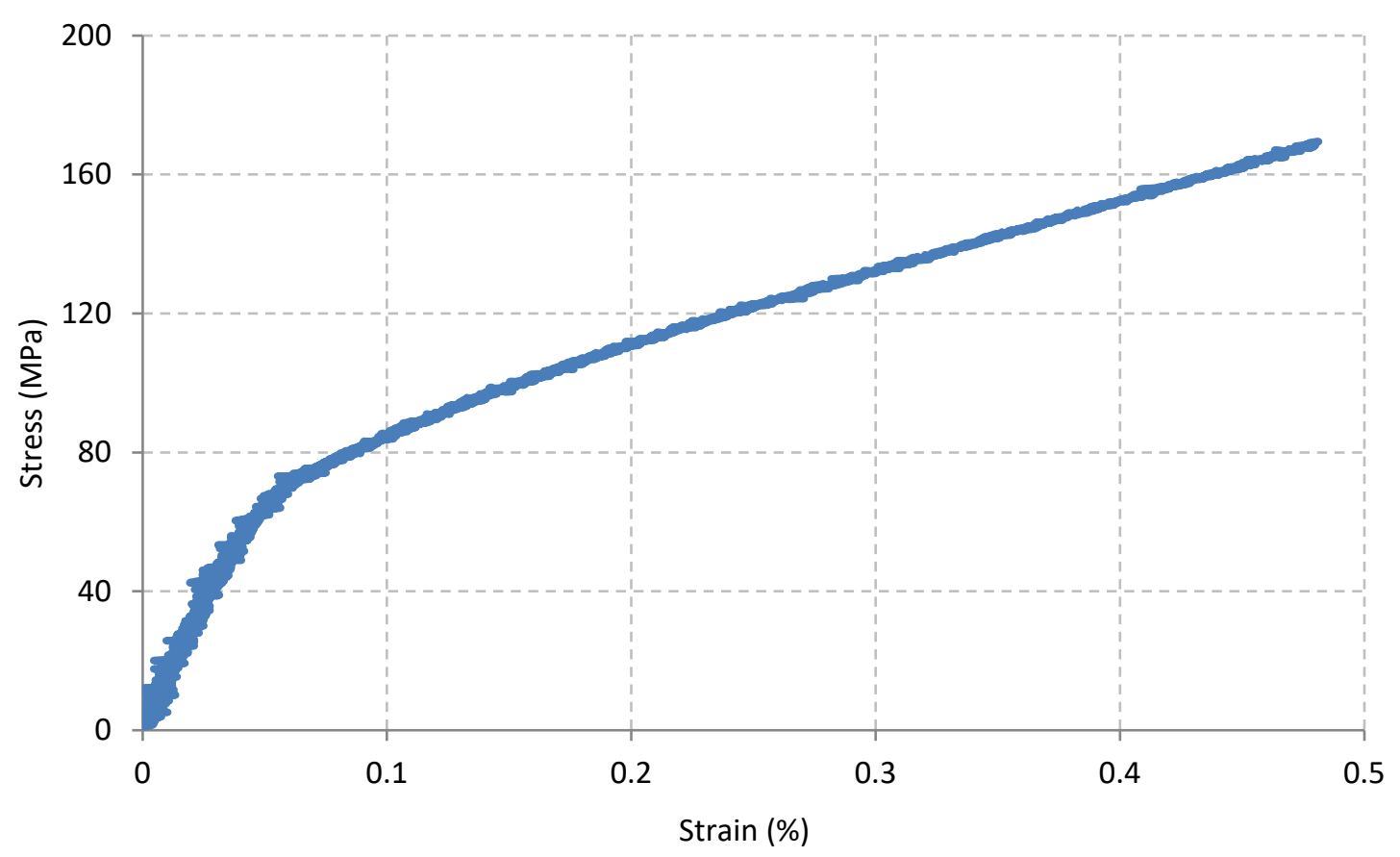

Figure 22: Stress-strain curve for specimen-10. 


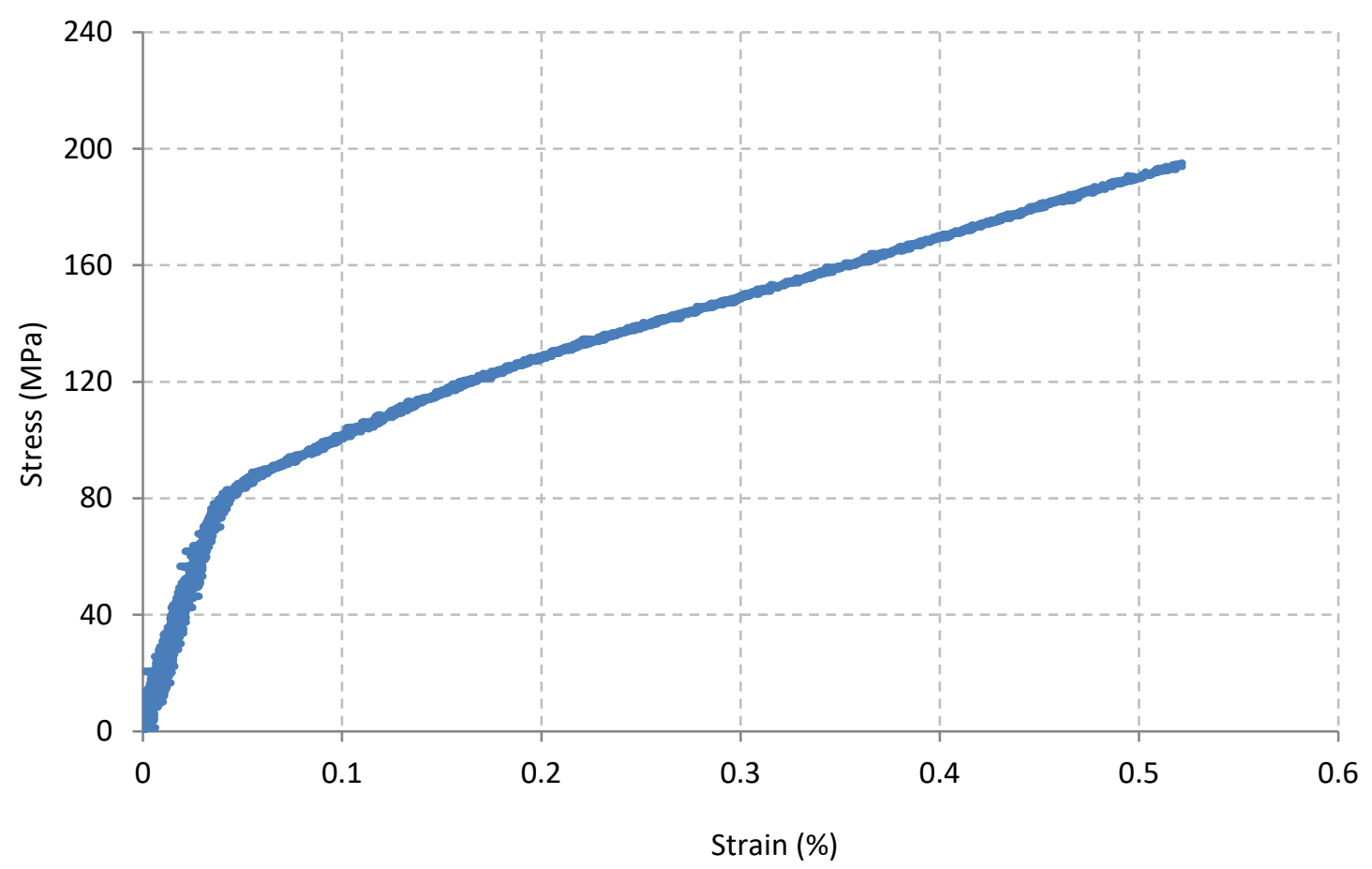

Figure 23: Stress-strain curve for specimen-11.

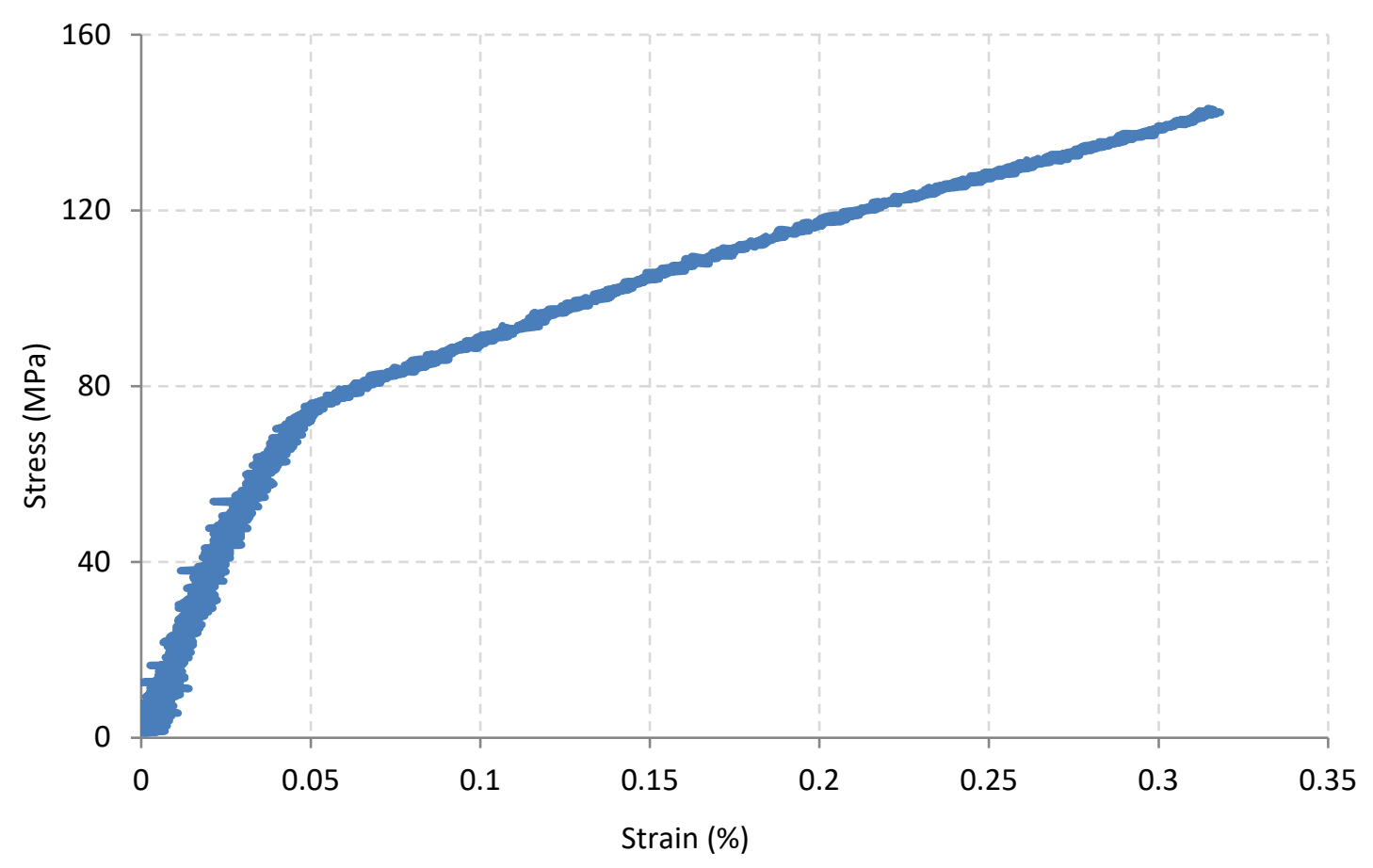

Figure 24: Stress-strain curve for specimen-12. 


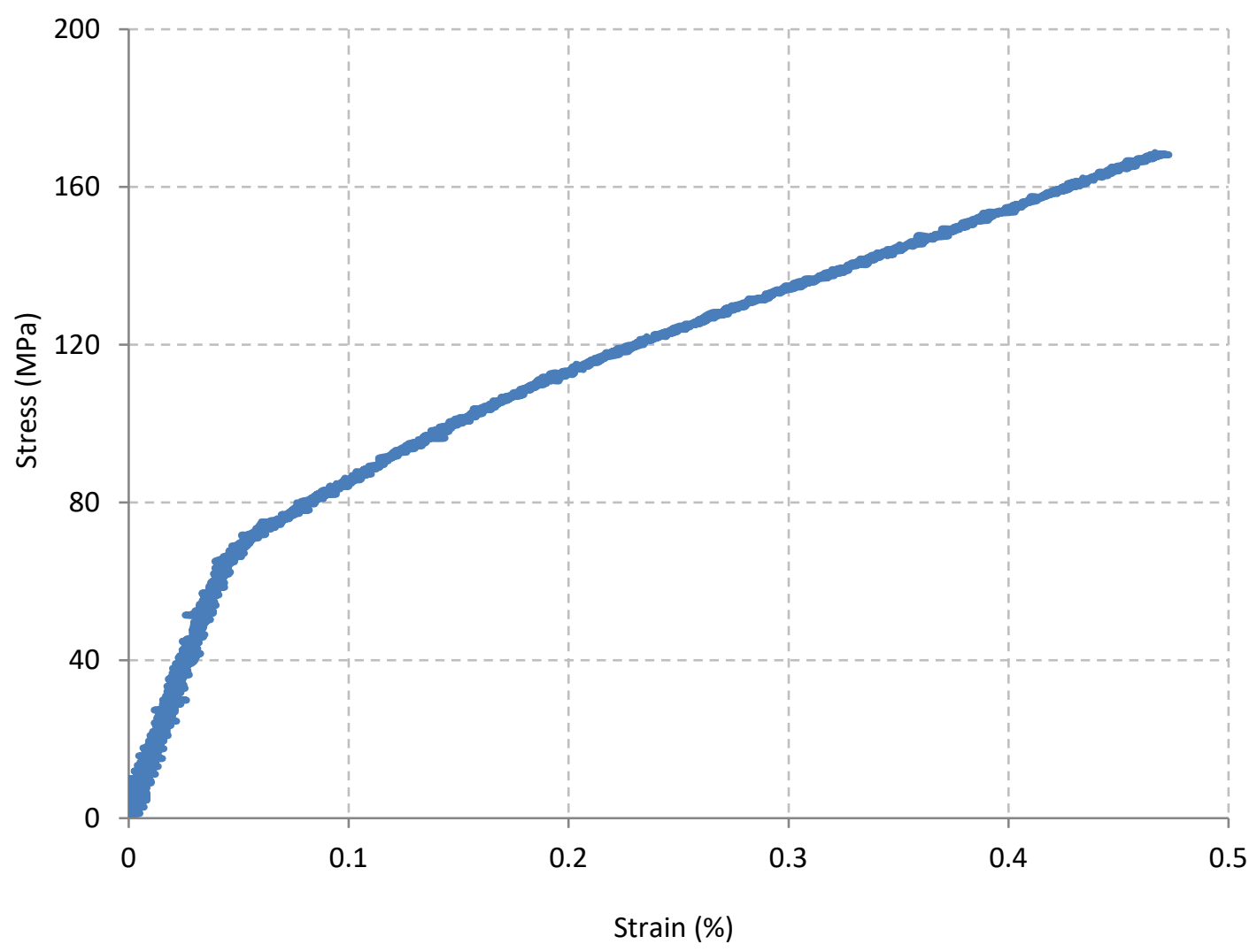

Figure 25: Stress-strain curve for specimen-13.

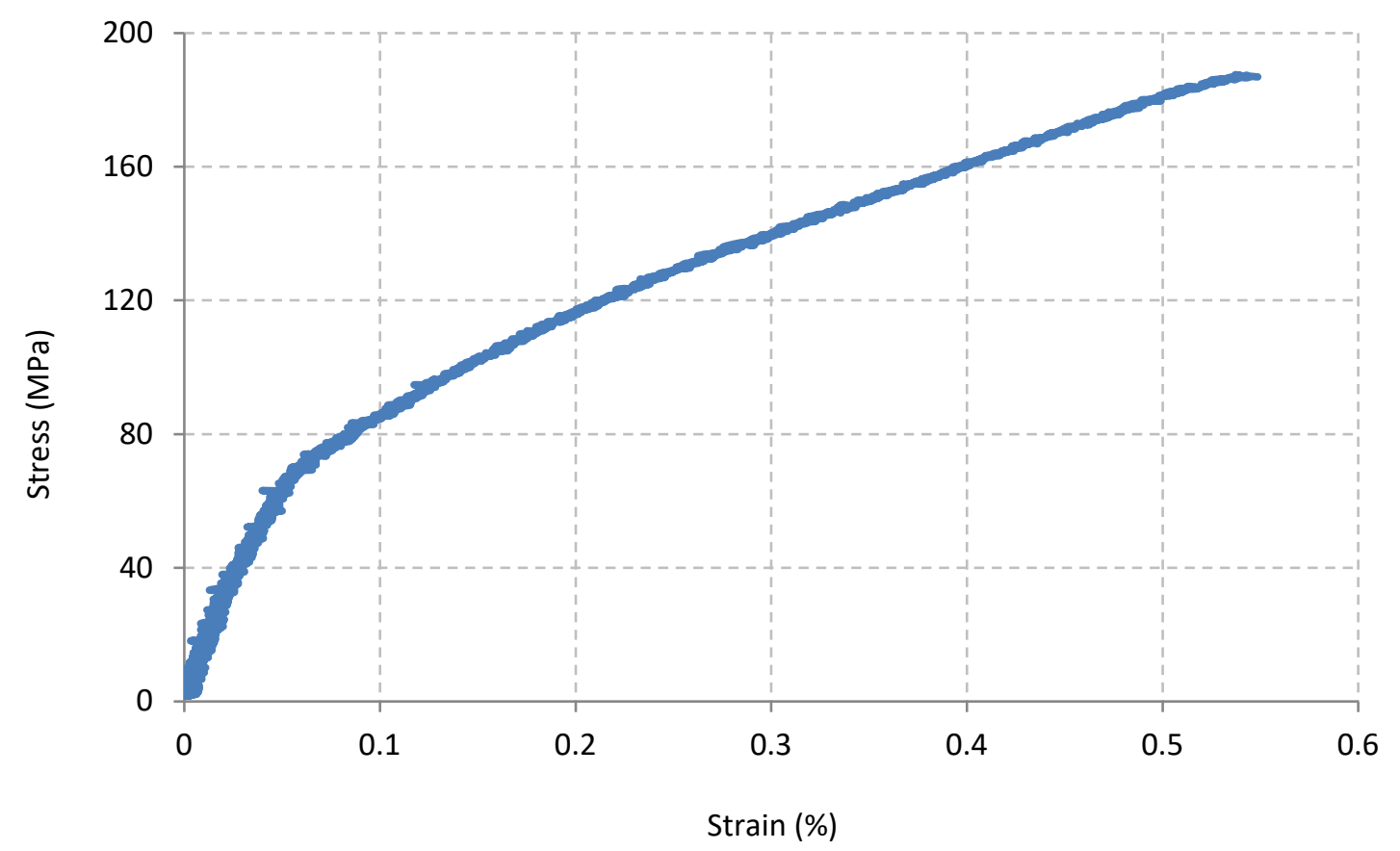

Figure 26: Stress-strain curve for specimen-1. 


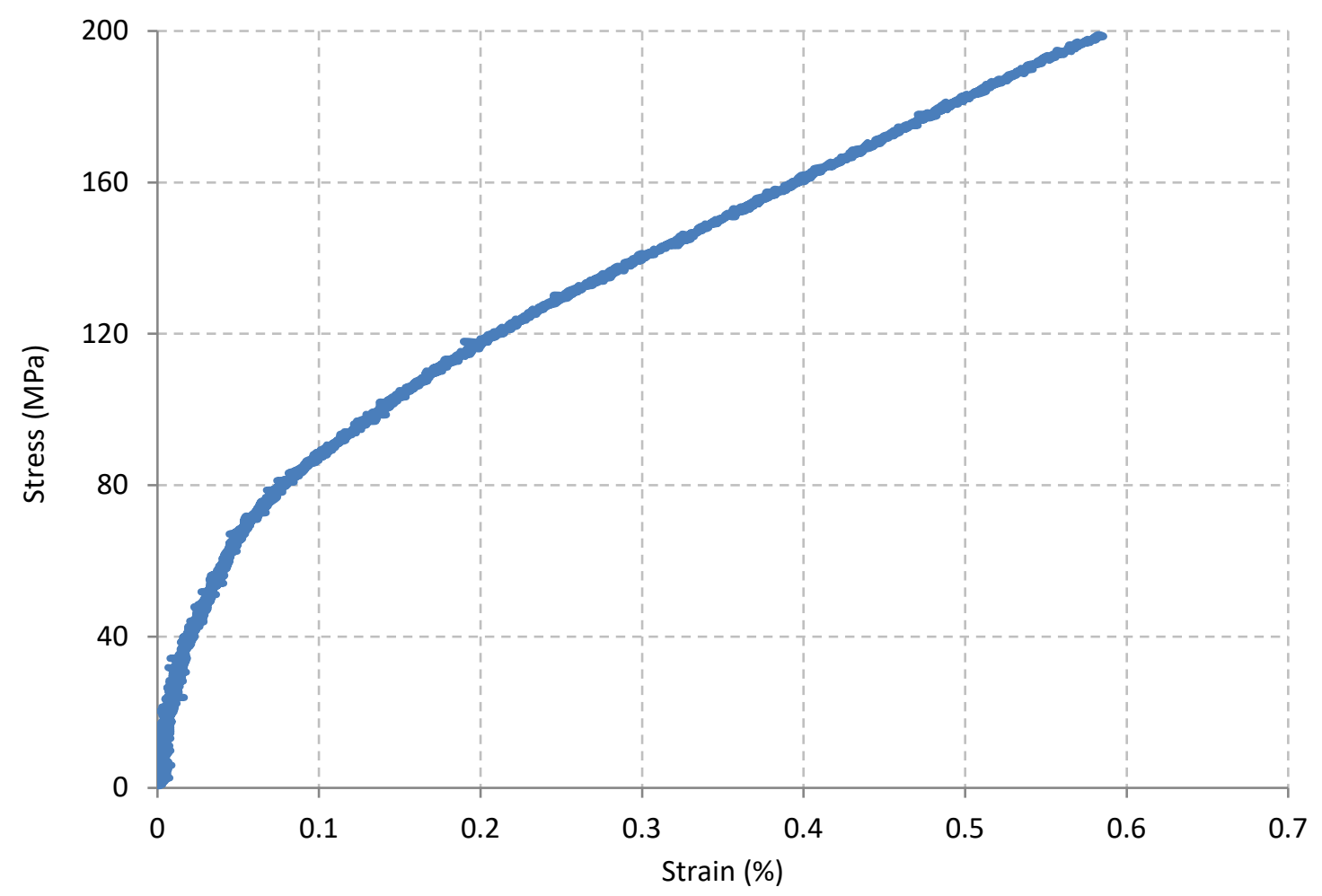

Figure 27: Stress-strain curve for specimen-2.

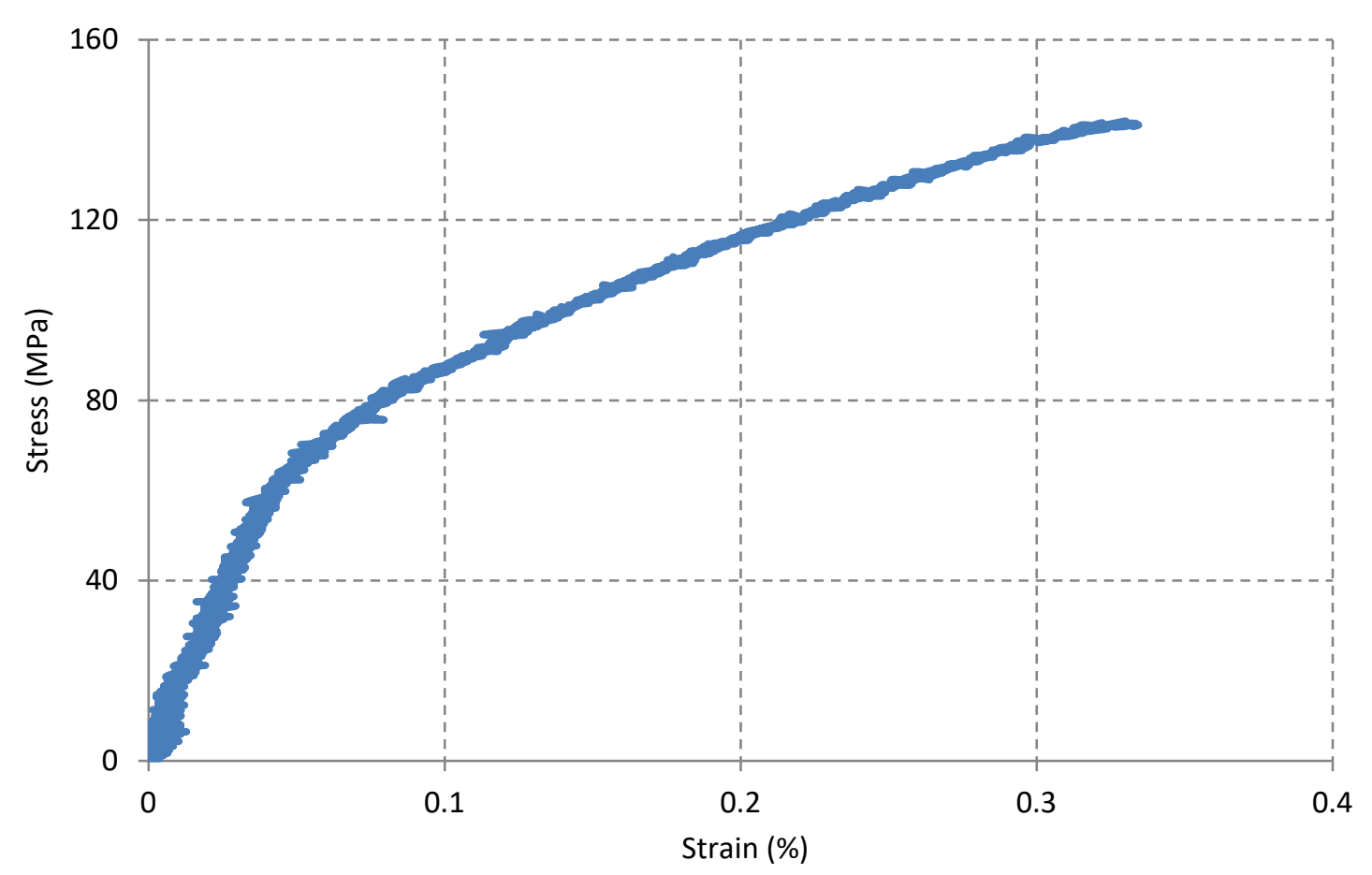

Figure 28: Stress-strain curve for specimen-3. 


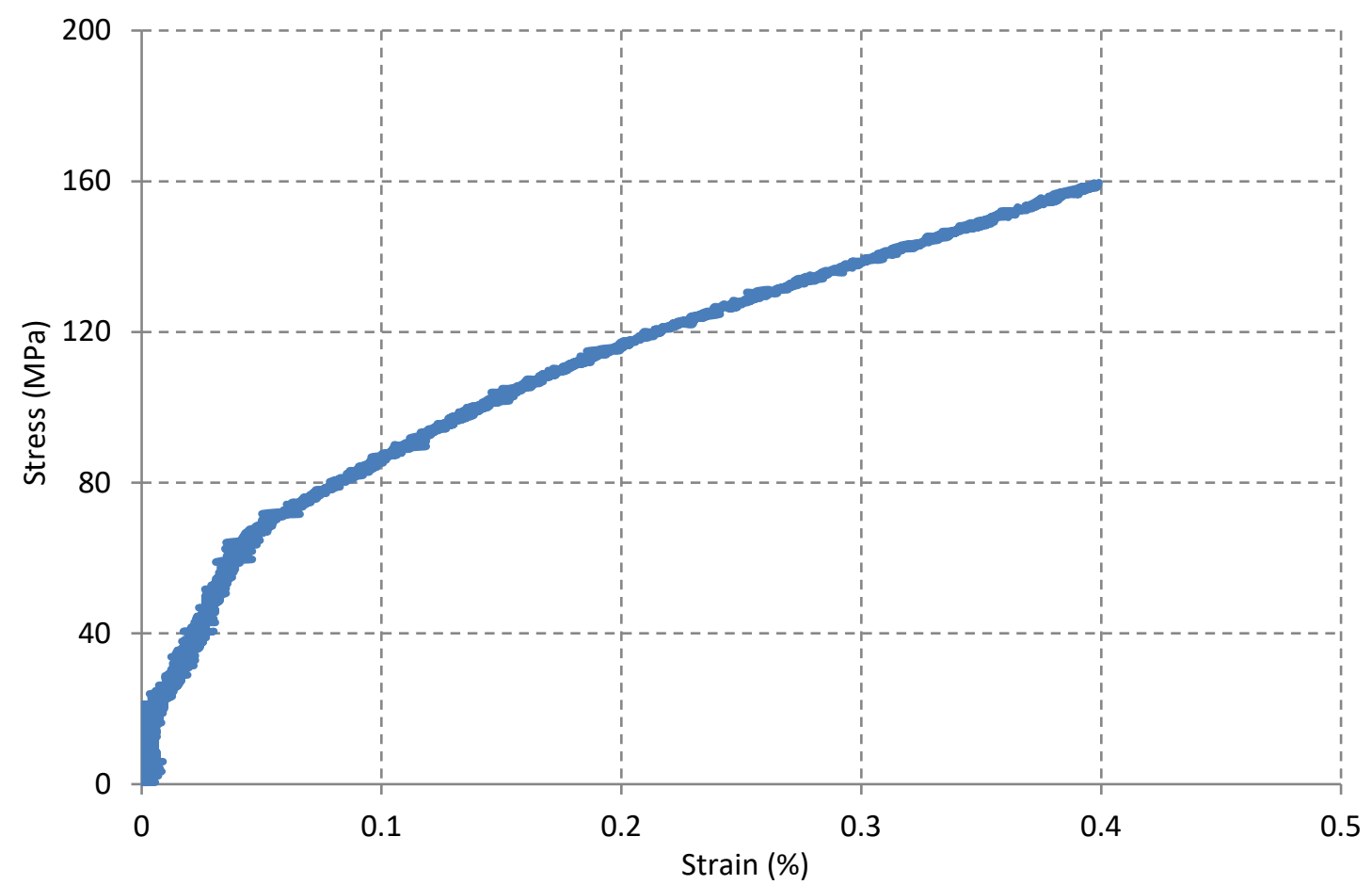

Figure 29: Stress-strain curve for specimen-4.

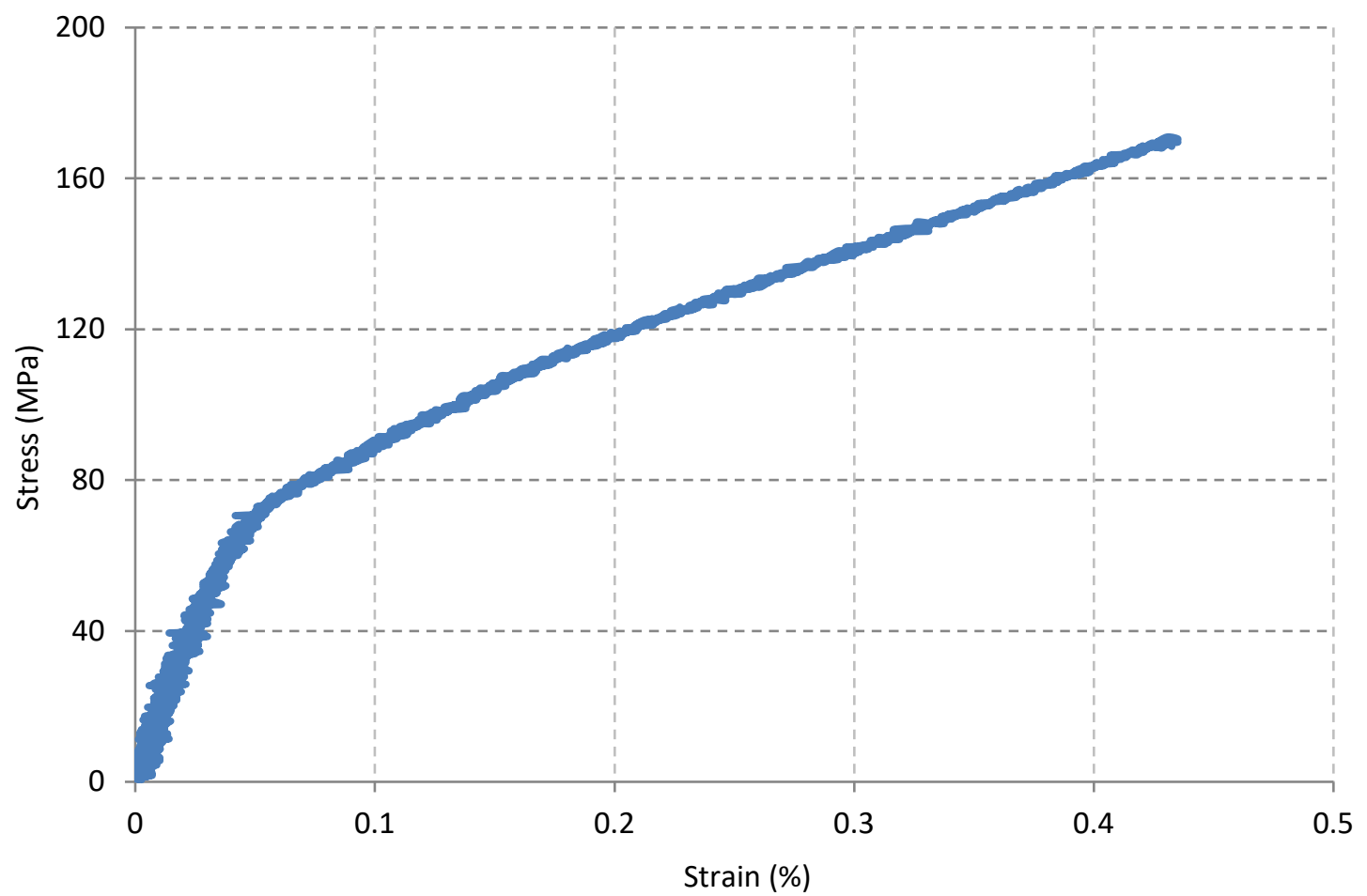

Figure 30: Stress-strain curve for specimen-8. 